Keywords: vacuum distillation, halide, hydroxide, plutonium

Retention: Permanent

\title{
Pilot-Scale Removal of Fluoride from Legacy Plutonium Materials using Vacuum Salt Distillation
}

R. A. Pierce and D. J. Pak

September 2012

Savannah River National Laboratory Savannah River Nuclear Solutions Aiken, SC 29808

Prepared for the U.S. Department of Energy under contract number DE-AC09-08SR22470.

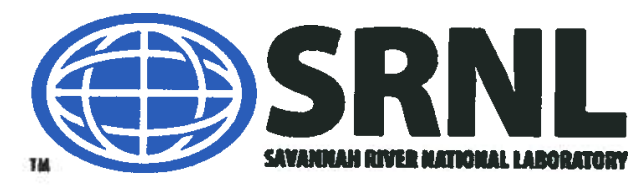




\section{DISCLAIMER}

This work was prepared under an agreement with and funded by the U.S. Government. Neither the U.S. Government or its employees, nor any of its contractors, subcontractors or their employees, makes any express or implied:

1. warranty or assumes any legal liability for the accuracy, completeness, or for the use or results of such use of any information, product, or process disclosed; or

2. representation that such use or results of such use would not infringe privately owned rights; or

3. endorsement or recommendation of any specifically identified commercial product, process, or service.

Any views and opinions of authors expressed in this work do not necessarily state or reflect those of the United States Government, or its contractors, or subcontractors.

Printed in the United States of America

Prepared for

U.S. Department of Energy 


\section{REVIEWS AND APPROVALS}

AUTHORS:

R.A. Pierce, Separations and Actinide Science Programs

Date

D.J. Pak, Mechanical Systems and Custom Equipment Development

Date

TECHNICAL REVIEW:

T.C. Shehee, Technical Reviewer

Date

Separations and Actinide Science Programs

J.E. Therrell, Technical Reviewer

Date

HB-Line Engineering

\section{APPROVAL:}

S.D. Fink, Manager

Date

Separations and Actinide Science Programs

S.L. Marra, Manager

Date

Environmental \& Chemical Process Technology Research Programs

K.P. Burrows, Manager

Date

Materials Disposition Engineering 


\section{EXECUTIVE SUMMARY}

Between September 2009 and January 2011, the Savannah River National Laboratory (SRNL) and HB-Line designed, developed, tested, and successfully deployed a system for the distillation of chloride salts. In 2011, SRNL adapted the technology for the removal of fluoride from fluoride-bearing salts. The method involved an in situ reaction between potassium hydroxide $(\mathrm{KOH})$ and the fluoride salt to yield potassium fluoride $(\mathrm{KF})$ and the corresponding oxide. The $\mathrm{KF}$ and excess $\mathrm{KOH}$ can be distilled below $1000^{\circ} \mathrm{C}$ using vacuum salt distillation (VSD). HBLine Engineering requested SRNL to expand the understanding of the technology and develop the equipment for use in a pilot-scale demonstration with plutonium-bearing materials.

SRNL has successfully demonstrated the removal of halide from $\mathrm{CaCl}_{2}, \mathrm{CaF}_{2}$ and $\mathrm{CeF}_{3}$ below $1000{ }^{\circ} \mathrm{C}$ at the pilot scale using VSD technology. At the initiation of the project, the fluoride specification was $7500 \mathrm{mg} / \mathrm{kg}$. Late in the project cycle, the specification was revised downward to $250 \mathrm{mg} / \mathrm{kg}$. The halides were removed from individual salts and mixtures of them. Although halide removal to the original target of $7500 \mathrm{mg} / \mathrm{kg}$ can be achieved in $120 \mathrm{~min}$ at $975^{\circ} \mathrm{C}$ under vacuum, at least $180 \mathrm{~min}$ at temperature is recommended to meet the revised target of $250 \mathrm{mg} / \mathrm{kg}$.

When other distillable salts, such as sodium chloride $(\mathrm{NaCl})$, were distilled with $\mathrm{CaCl}_{2}, \mathrm{CaF}_{2}$, and $\mathrm{CeF}_{3}$, no additional $\mathrm{KOH}$ was required to achieve the MOX specification. Reduction of the initial halide concentration in the feed material, and hence the total amount of $\mathrm{KOH}$ added, did not reduce process effectiveness.

Non-radioactive pilot-scale testing (350-g scale) removed chloride and fluoride to less than 250 $300 \mathrm{mg} / \mathrm{kg}$ with $30-50 \%$ molar excess $\mathrm{KOH}$ and a furnace cycle of $180 \mathrm{~min}$ at $975^{\circ} \mathrm{C}$. The initial MOX specification of $7500 \mathrm{mg} / \mathrm{kg}$ was also achieved with $10-20 \%$ molar excess $\mathrm{KOH}$, but with much less margin. A furnace cycle of 120 min at $975{ }^{\circ} \mathrm{C}$ with $10-12 \%$ molar excess $\mathrm{KOH}$ can achieve $7500 \mathrm{mg} / \mathrm{kg}$ residual fluoride, but not consistently within analytical uncertainty.

Tests using lower percentages of excess $\mathrm{KOH}$ produce products that are easily reduced to powder. When a nominal $50 \%$ molar excess of $\mathrm{KOH}$ is used, the post-VSD product requires some grinding to form a powder. For a nominal excess of $25-30 \%$ molar excess of $\mathrm{KOH}$, the product readily crumbles when a small amount of force is applied. At $10 \%$ molar excess, the product reverts to a powder form readily. Consequently, $\mathrm{KOH}$ additions should be minimized. There is no correlation between the residual $\mathrm{K}$ concentration of the post-VSD product and product consistency. Based on pilot-scale testing, the recommended flowsheet entails $30 \%$ molar excess $\mathrm{KOH}$ and a furnace cycle of $180 \mathrm{~min}$ at $975^{\circ} \mathrm{C}$.

Testing was completed with a plutonium-bearing material (S002250) which contained $5.14 \mathrm{wt} \%$ fluoride. Issues with vacuum pump reliability were encountered during testing. In experiments with $80-100 \mathrm{~g}$ of feed material, $23 \%$ of the fluoride was removed after $120 \mathrm{~min}$ at $975^{\circ} \mathrm{C}$ under poor vacuum ( $>5$ torr). With adequate vacuum ( $\sim 0.06$ torr), improved fluoride removal was observed. After 15 min at $975^{\circ} \mathrm{C}$ with $21 \%$ molar excess $\mathrm{KOH}$, fluoride was reduced by $72 \%$ to $14,300 \mathrm{mg} / \mathrm{kg}$. After $35 \mathrm{~min}$ at $975{ }^{\circ} \mathrm{C}$ with $49 \%$ molar excess $\mathrm{KOH}$, fluoride was reduced by $91 \%$ to $4410 \mathrm{mg} / \mathrm{kg}$. When distilled for $65 \mathrm{~min}$ at $975{ }^{\circ} \mathrm{C}$ with $49 \%$ molar excess $\mathrm{KOH}$, fluoride was reduced by $98 \%$ to $1070 \mathrm{mg} / \mathrm{kg}$. These tests demonstrate that the $\mathrm{S} 002250$ material fluoride concentration can be reduced to meet the initial MOX feed specification of $7500 \mathrm{mg} / \mathrm{kg}$. Extrapolation of the data shows that the updated specification of $250 \mathrm{mg} / \mathrm{kg}$ would be achieved in about $90 \mathrm{~min}$. 
SRNL evaluated four disposable liner designs at the pilot scale for easy disposal of distilled salt. Two designs are superior. The recommended design uses a stainless-steel disposable liner attached to a re-usable tapered end cap that matches the tapered region in the VSD vacuum chamber. The liner design was effective in collecting greater than $99.9 \%$ of the salt. However, even this small amount of salt over time could lead to the liner getting stuck in the vacuum chamber. Consequently, it is recommended that damp cloth wiping of the vessel wall be completed after each unit operation.

The use of $\mathrm{KOH}$ in the process increases the chemical attack and corrosion of the Alloy 600 product boats and, to a lesser degree, the vacuum chamber. As with testing that did not use $\mathrm{KOH}$, the boat surface eventually passivates to an extent such that the life of an Alloy 600 boat would exceed 100 production cycles. If necessary, an alumina material can be used which better resists chemical attack.

Water is a byproduct of the reaction between $\mathrm{KOH}$ and multivalent halide salts. The presence of water in the off gas stream from the vacuum chamber can negatively impact the vacuum pump. Testing demonstrated that a calcium sulfate absorbent can be used in line to remove most of the moisture. The quantity of water reaching the vacuum pump is less than what was observed for chloride salt removal studies without $\mathrm{KOH}$. As a result, the use of the dry vacuum pump in conjunction with the absorbent should be adequate for fluoride-removal trials in HB-Line.

During pilot-scale testing, salts deposited on the vacuum chamber door occurred, likely due to the volatility of $\mathrm{KOH}$. The salt on the door rapidly absorbs moisture from the air, suggesting that it is $\mathrm{KOH}$. Although less than one gram, the presence of salt on the door poses a potential safety issue. The deposited salt is a high-surface-area material which reacts vigorously with water. When scraped with a metal tool, the material sparks. However, when the vacuum chamber door is opened and the salt has unrestricted contact with the atmosphere, it absorbs moisture and passivates within several minutes. Pilot-scale testing has shown that the material can be passivated with the door closed by allowing air into the chamber during system cooling. However, systematic testing in a configuration comparable to HB-Line has not yet been conducted.

The next major step for the program entails pilot-scale testing with radioactive materials in HB-Line. To complete this demonstration, five minor tasks are recommended. 1) Finalize the boat design including an assessment of whether alumina is required. 2) Identify the process conditions needed to passivate salts that deposit on the vacuum chamber door; testing equipment should be configured comparably to HB-Line. 3) Develop and fabricate a tool for compacting and disposing of disposable liners. 4) Evaluate the benefits of a 240 -min furnace heating cycle at $975^{\circ} \mathrm{C}$ instead of a 180 -min cycle. 5) Evaluate fluoride removal efficiency at $950^{\circ} \mathrm{C}$. 


\section{TABLE OF CONTENTS}

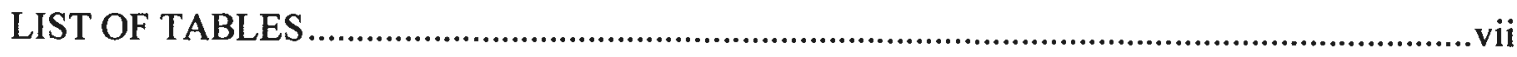

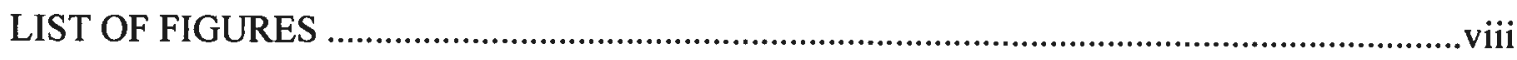

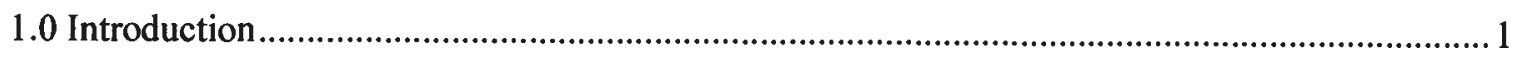

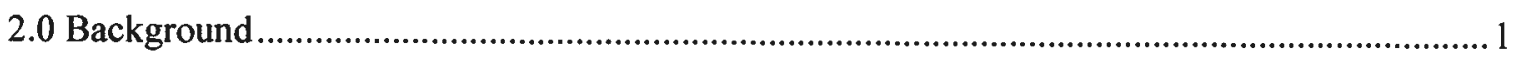

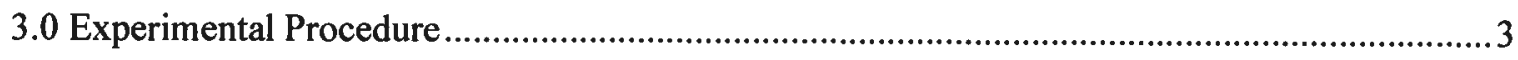

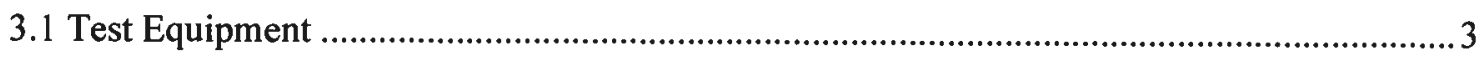

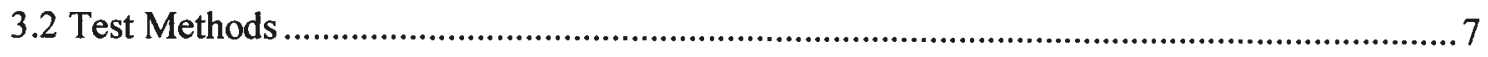

3.2.1 Small-Scale Process Demonstration ........................................................................ 7

3.2.2 Pilot-Scale Process Demonstration ........................................................................... 10

3.2.3 Demonstration with Plutonium Compounds.......................................................... 10

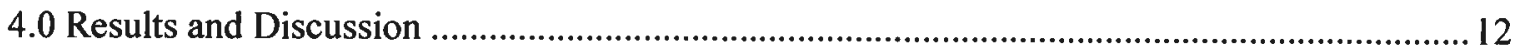

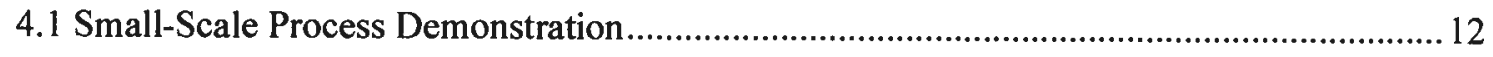

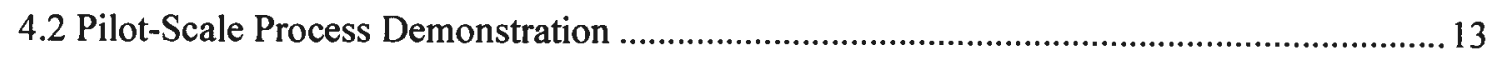

4.3 Demonstration with Plutonium Compound .................................................................. 15

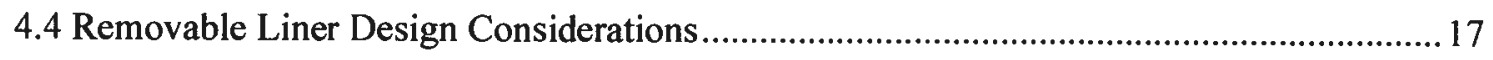

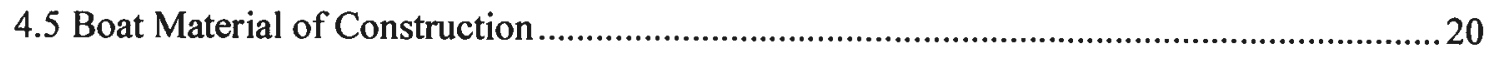

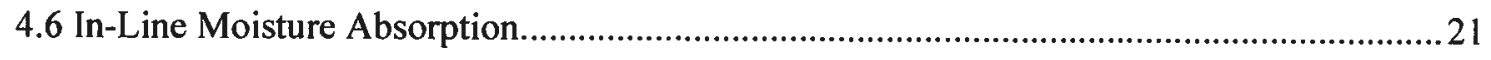

4.7 Salt Deposition on the Vacuum Chamber Door .............................................................22

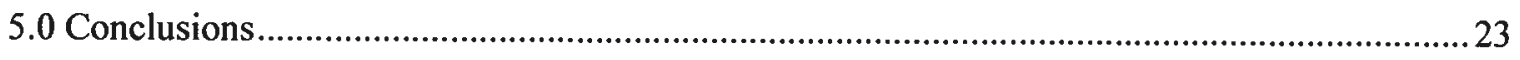

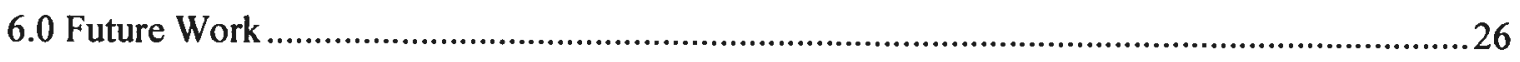

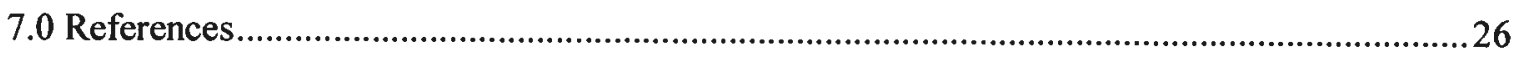

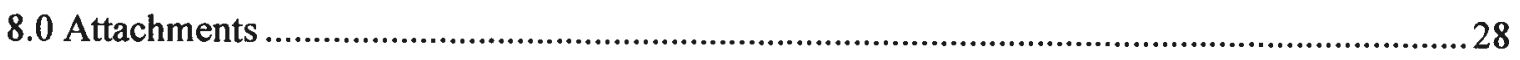

8.1 Attachment 1: Photographs of Residual Salt in the Vacuum Chamber...............................28 


\section{LIST OF TABLES}

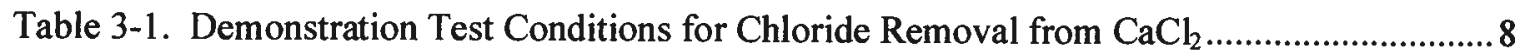

Table 3-2. Demonstration Test Conditions for Fluoride Removal from $\mathrm{CaF}_{2}$ and $\mathrm{CeF}_{3} \ldots \ldots \ldots \ldots . . . .9$

Table 3-3. Demonstration Test Conditions for Fluoride Removal from S002250...................... 11

Table 4-1. Small-Scale Demonstration Test Results.............................................................. 12

Table 4-2. Pilot-Scale Demonstration Test Results .............................................................. 14

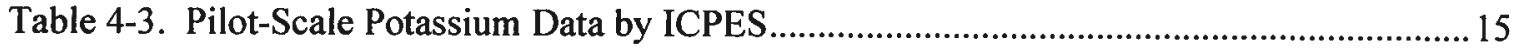

Table 4-4. Demonstration Test Results for Pu Sample S002250 ........................................... 16

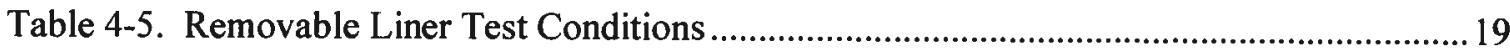




\section{LIST OF FIGURES}

Figure 2-1. Comparison of Chloride and Fluoride Salt Volatility .............................................2

Figure 2-2. Salt Volatility Comparisons for Fluoride Removal by VSD ....................................... 3

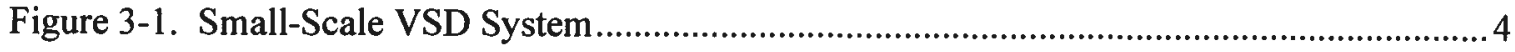

Figure 3-2. Intermediate-Scale Vacuum Chamber................................................................. 4

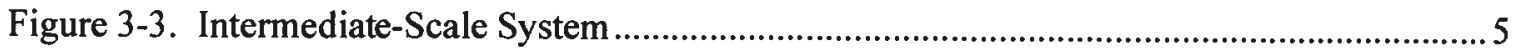

Figure 3-4. Comparison of VSD Liner Concepts .................................................................5

Figure 3-5. Removable Liner Concept with Disposable Liner and Re-usable End Cap.................6

Figure 3-6. Disposable Liner with Re-usable Tapered End Cap ...............................................6

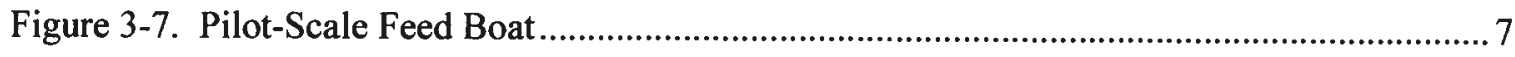

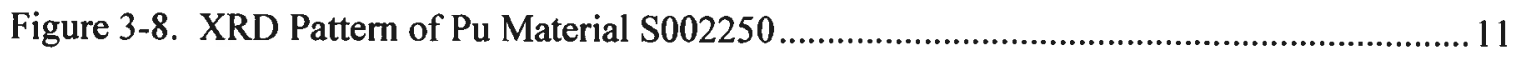

Figure 4-1. S002250 after Reaction with $\mathrm{KOH}$ followed by VSD for $15 \mathrm{~min}$............................. 16

Figure 4-2. Distillation of Fluoride from Sample S002250 ................................................. 17

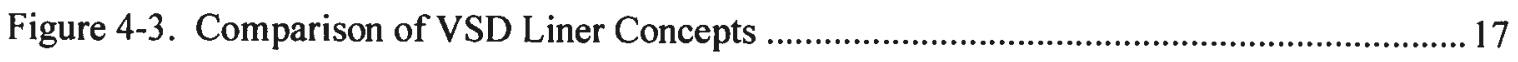

Figure 4-4. Typical Salt Deposition Pattern in Vacuum Chamber - Concept \#1 ......................... 18

Figure 4-5. Typical Salt Deposition Pattern in Removable Liner............................................... 18

Figure 4-6. Alloy 600 Feed Boat before and after Pilot-Scale Testing .....................................21

Figure 4-7. Drierite ${ }^{\mathrm{TM}}$ Column for Moisture Absorption Upstream of Vacuum Pump ................ 22

Figure 4-8. Salt Deposition on Vacuum Chamber Door - Tests 34 and 38..............................2 23 


\section{LIST OF ABBREVIATIONS}

$\begin{array}{ll}\text { AD } & \text { Analytical Development } \\ \text { DI } & \text { de-ionized } \\ \text { DOE } & \text { Department of Energy } \\ \text { IC } & \text { ion chromatography } \\ \text { ICPES } & \text { inductively coupled plasma emission spectroscopy } \\ \text { ID } & \text { inside diameter } \\ \text { KAMS } & \text { K-Area Material Storage } \\ \text { MFFF } & \text { MOX Fuel Fabrication Facility } \\ \text { MOX } & \text { mixed oxide } \\ \text { OD } & \text { outside diameter } \\ \text { SRNL } & \text { Savannah River National Laboratory } \\ \text { SRS } & \text { Savannah River Site } \\ \text { VSD } & \text { vacuum salt distillation } \\ \text { XRD } & \text { X-ray diffraction }\end{array}$




\subsection{Introduction}

Vacuum distillation of chloride salts from plutonium oxide $\left(\mathrm{PuO}_{2}\right)$ and simulant $\mathrm{PuO}_{2}$ has been previously demonstrated at Department of Energy (DOE) sites using kilogram quantities of chloride salt. ${ }^{[1-2]}$ The apparatus for vacuum distillation contains a zone heated using a furnace and a zone actively cooled using either recirculated water or compressed air. During a vacuum distillation operation, a sample boat containing the feed material is placed into the apparatus while it is cool, and the system is sealed. The system is evacuated using a vacuum pump. Once a sufficient vacuum is attained, heating begins. Volatile salts distill from the heated zone to the cooled zone where they condense, leaving behind the non-volatile materials in the feed boat.

The application of vacuum salt distillation (VSD) is of interest to the HB-Line Facility and the MOX (Mixed Oxide) Fuel Fabrication Facility (MFFF) at the Savannah River Site (SRS). Both facilities are involved in efforts to disposition excess fissile materials. Many of these materials contain chloride and fluoride salt concentrations which make them unsuitable for dissolution without prior removal of the chloride and fluoride salts.

Between September 2009 and January 2011, the Savannah River National Laboratory (SRNL) and HB-Line designed, developed, tested, and successfully deployed a system for the distillation of chloride salts. ${ }^{[3]}$ Fluoride salts of interest are less-volatile than the corresponding chloride salts. Consequently, an alternate approach was required for the removal of fluoride without significantly increasing the operating temperature. Between May and September 2011, SRNL adapted the technology for the removal of fluoride. ${ }^{[4]}$ The method involved an in situ reaction between potassium hydroxide $(\mathrm{KOH})$ and the fluoride salt to yield potassium fluoride (KF) and the corresponding oxide. The $\mathrm{KF}$ and excess $\mathrm{KOH}$ were distilled below $1000{ }^{\circ} \mathrm{C}$.

HB-Line Engineering requested SRNL to expand the understanding of the technology and develop equipment for use in a pilot-scale demonstration with plutonium-bearing materials. ${ }^{[5-6]}$ The additional studies involved the use of non-radioactive simulants for flowsheet optimization and demonstration of engineering concepts. Plutonium-bearing materials were used for demonstration of the technology on actual excess $\mathrm{Pu}$ materials. This report discusses nonradioactive testing of small-scale and pilot-scale systems and radioactive testing of a small-scale system.

When this project was initiated, the fluoride target was $7500 \mathrm{mg} / \mathrm{kg} .{ }^{[5]}$ Much of the data contained in this report focused on achieving that target. Late in the project cycle (June 2012), the specification was drastically reduced to a combined fluoride and chloride concentration of less than $250 \mathrm{mg} / \mathrm{kg} .{ }^{[7]}$ The data is also analyzed against the revised target.

\subsection{Background}

VSD technology takes advantage of the large difference in volatility between alkali halide salts and $\mathrm{PuO}_{2}$. As has been demonstrated, $\mathrm{NaCl}$ and $\mathrm{KCl}$ are sufficiently volatile that they can be distilled from $\mathrm{PuO}_{2}$ at a satisfactory rate under vacuum above $900{ }^{\circ} \mathrm{C}^{[8]}$ Alkaline-earth halides and actinide halides also have a large enough difference in volatility from $\mathrm{PuO}_{2}$ to enable distillation; however, they are not sufficiently volatile below $1000^{\circ} \mathrm{C}$ to allow distillation at a rate sufficient for production-scale operations in HB-Line. A comparison of volatility of chloride and fluoride salts is shown in Figure 2-1. ${ }^{[9]}$ 


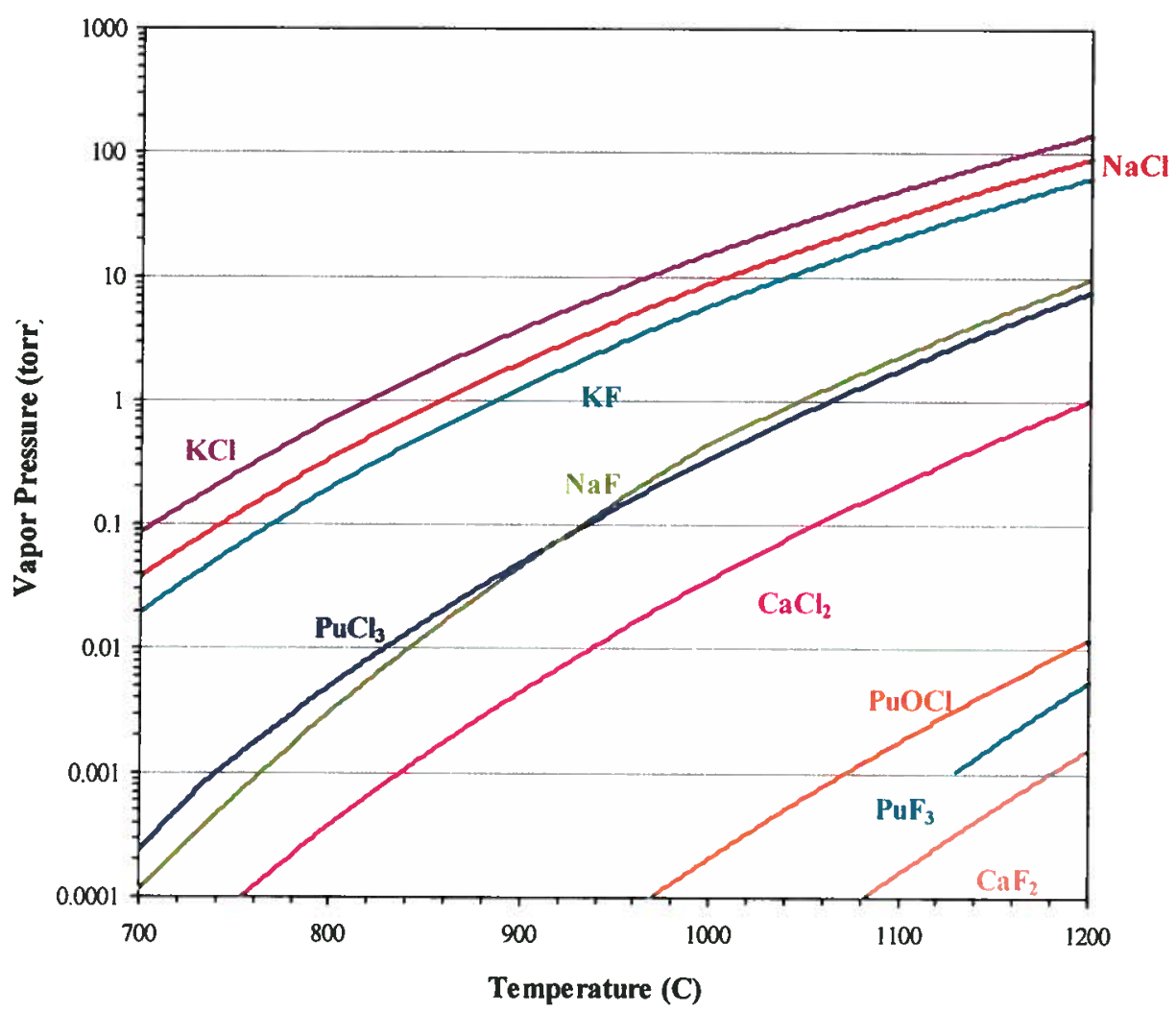

Figure 2-1. Comparison of Chloride and Fluoride Salt Volatility

It was shown that sodium hydroxide $(\mathrm{NaOH})$ or $\mathrm{KOH}$ react with $\mathrm{CaCl}_{2}$ and $\mathrm{PuF}_{3}$ according to reactions 1 and $2 .{ }^{[4]}$

$$
\begin{aligned}
& \mathrm{CaF}_{2}+2 \mathrm{KOH} \rightarrow \mathrm{CaO}+2 \mathrm{KF}+\mathrm{H}_{2} \mathrm{O} \\
& 2 \mathrm{PuF}_{3}+6 \mathrm{KOH}+1 / 2 \mathrm{O}_{2} \rightarrow 2 \mathrm{PuO}_{2}+6 \mathrm{KF}+3 \mathrm{H}_{2} \mathrm{O}
\end{aligned}
$$

After reaction 1 occurs, the less-volatile alkaline earth and actinide halide salts are converted to oxides and the associated halide exchanged to form either $\mathrm{KF}$ or $\mathrm{NaF}$, which is sufficiently volatile below $1000^{\circ} \mathrm{C}$. Furthermore, $\mathrm{KOH}$ is more volatile than $\mathrm{KF}$ or $\mathrm{NaF}$, which offers the potential for excess $\mathrm{KOH}$ to be distilled along with $\mathrm{KF}$ or NaF. Figure 2-2 shows the relative volatility of $\mathrm{KOH}$ and the relevant halide salts from Figure 2-1. ${ }^{[9]}$ The net result is that the distilled product shows a change from $\mathrm{CaCl}_{2}$ and $\mathrm{CaF}_{2}$ to $\mathrm{CaO}$ and from $\mathrm{PuCl}_{3}$ and $\mathrm{PuF}_{3}$ to $\mathrm{PuO}_{2}$. $\mathrm{PuO}_{2}$ is not shown in Figure 2-1 because the volatility of $\mathrm{PuO}_{2}$ is about seven of orders of magnitude lower than $\mathrm{CaF}_{2}$ (to the right of $\mathrm{CaF}_{2}$ in Figure 2-1); for comparison, the volatility of $\mathrm{CaF}_{2}$ is about seven orders of magnitude lower than $\mathrm{KCl}$ and $\mathrm{NaCl}$. 


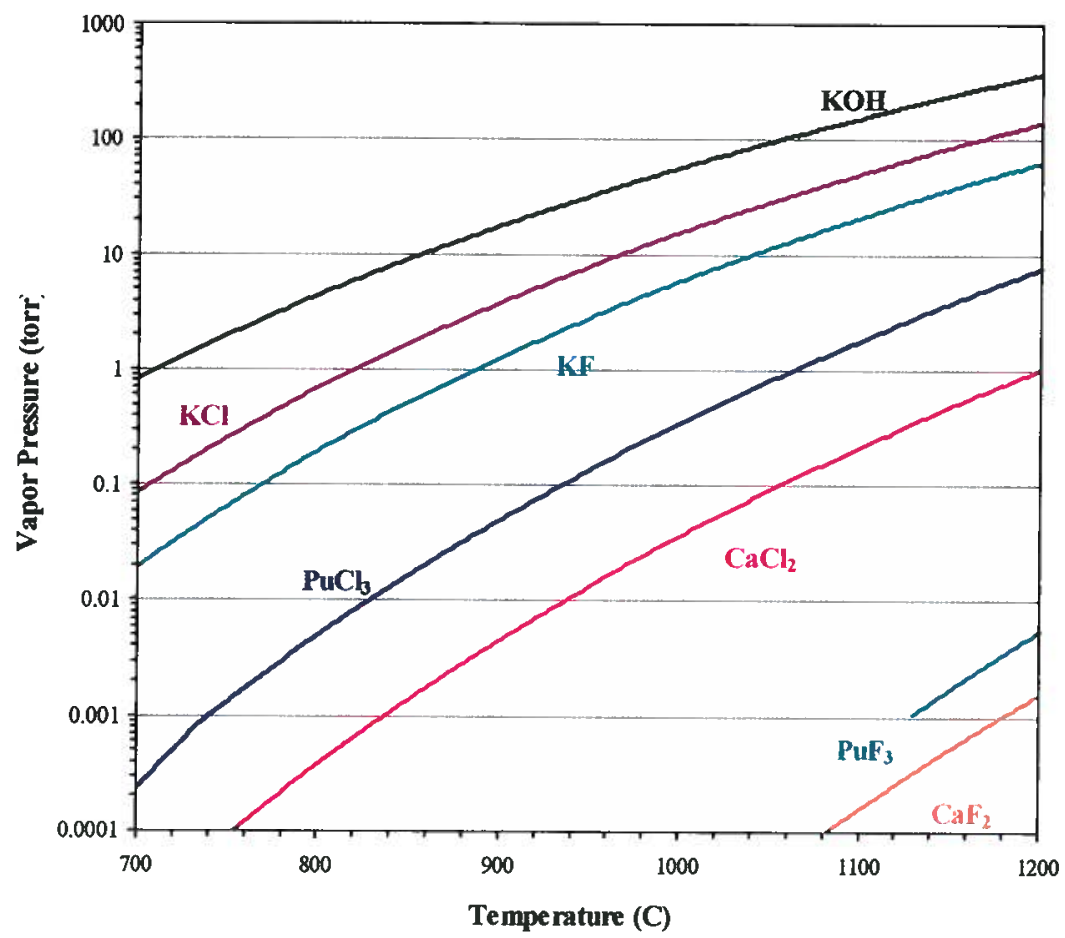

Figure 2-2. Salt Volatility Comparisons for Fluoride Removal by VSD

\subsection{Experimental Procedure}

\subsection{Test Equipment}

Three different test units were used: 1) a non-radioactive small-scale unit, 2) a non-radioactive pilot-scale unit of dimensions similar to the VSD unit deployed in HB-Line, and 3) a radioactive small-scale unit. The non-radioactive small-scale distillation unit was fabricated from Alloy 600 by the SRNL Machine Shop and consisted of a $5-\mathrm{cm}$ inside diameter (ID) heated zone $(23 \mathrm{~cm}$ long) which opened up to a $8.5-\mathrm{cm}$ ID cooled zone $(21 \mathrm{~cm}$ long). The apparatus used a stainlesssteel cooling coil wrapped around the outside of the $8.5-\mathrm{cm}$ ID section and was cooled using $15^{\circ} \mathrm{C}$ water. During testing, the system was closed and evacuated using a Pyrex ${ }^{\mathrm{TM}}$ end-flange and Viton ${ }^{\mathrm{TM}} \mathrm{o}$-ring. The end-flange was held in place only by the vacuum, negating the need for additional over-pressure protection measures. The end-flange was designed to enable the operator to view the interior of the VSD unit during testing. A photograph of the VSD setup is shown in Figure 3-1.

The non-radioactive pilot-scale system was fabricated from Alloys 600 and 690 by the SRNL Machine Shop. Its physical dimensions and features correspond to the vacuum chamber deployed in HB-Line. It consisted of a $28-\mathrm{cm}$ long $7.5-\mathrm{cm}$ ID heated zone which opened to a $53-\mathrm{cm}$ long $10-\mathrm{cm}$ ID cooled zone. The cooled zone contained $32 \mathrm{~cm}$ of $6.4-\mathrm{mm}$ diameter stainless-steel cooling coil wrapped around it. The VSD vacuum chamber was heated using a Carbolite GHC $12 / 450$ three-zone tube furnace rated at $3120 \mathrm{~W}$. It was cooled with either $20^{\circ} \mathrm{C}$ water or compressed air. The system was evacuated using an Edwards RV5 oil vacuum pump. The vacuum pump was connected to the vacuum chamber using stainless-steel bellows hose. A picture of the vacuum chamber is shown in Figure 3-2, and a picture of the VSD apparatus in the furnace is provided in Figure 3-3. The end cap was fabricated from 304L stainless steel with a 
groove for a Viton ${ }^{\mathrm{TM}}$ o-ring. Vacuum was measured adjacent to the flange with an Edwards Pirani $^{\mathrm{TM}}$ gauge. During the test program, the equipment shown in Figure 3-2 was modified to have a tapered transition piece instead of a squared transition. This change was implemented for testing alternate liner designs.

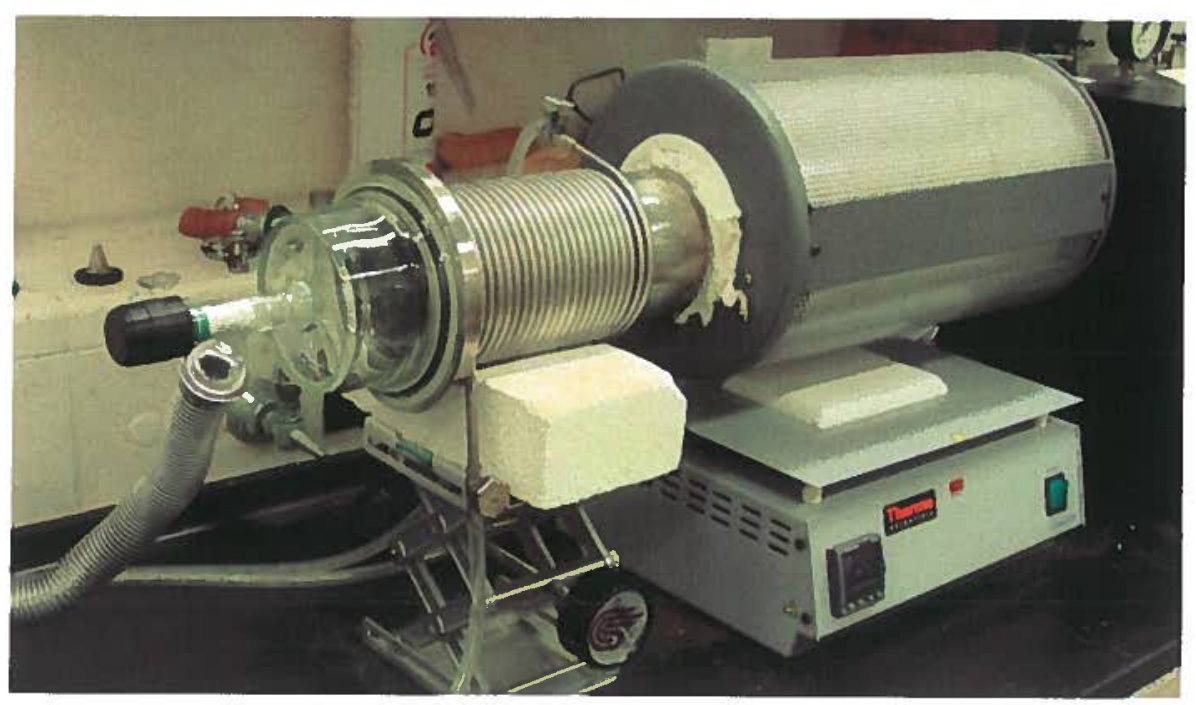

Figure 3-1. Small-Scale VSD System

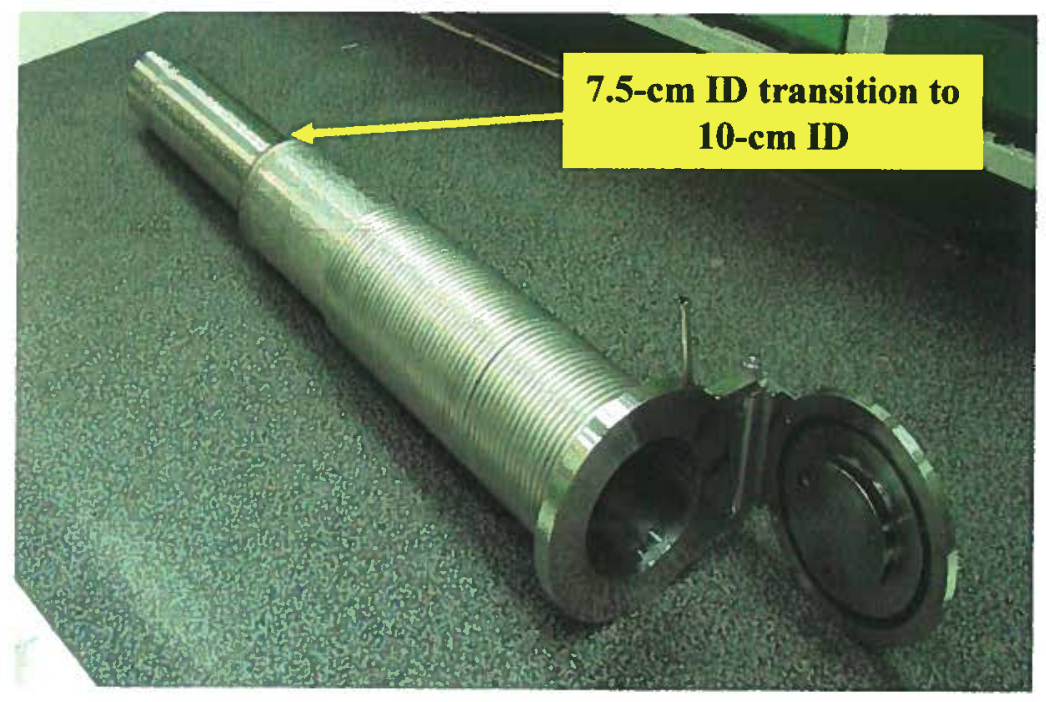

Figure 3-2. Intermediate-Scale Vacuum Chamber 


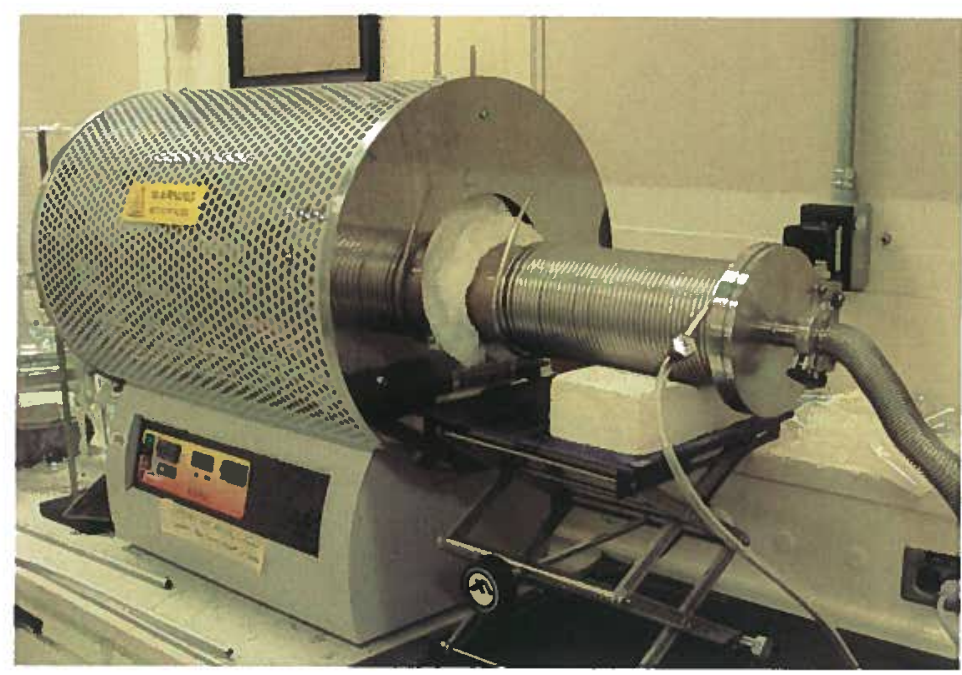

Figure 3-3. Intermediate-Scale System

The radioactive small-scale unit has dimensions similar to that of the non-radioactive small scale unit with the exception of the cooled section being $38 \mathrm{~cm}$ long instead of $21 \mathrm{~cm}$. Pictures and a discussion of the details of the unit are provided elsewhere. ${ }^{[10]}$

For non-radioactive pilot-scale testing, four removable liner concepts were used for salt collection. Removable liners were also deployed in small-scale tests, but more as a matter of convenience than studying their effectiveness. A comparison of the four pilot-scale liner concepts is provided in Figure 3-4.
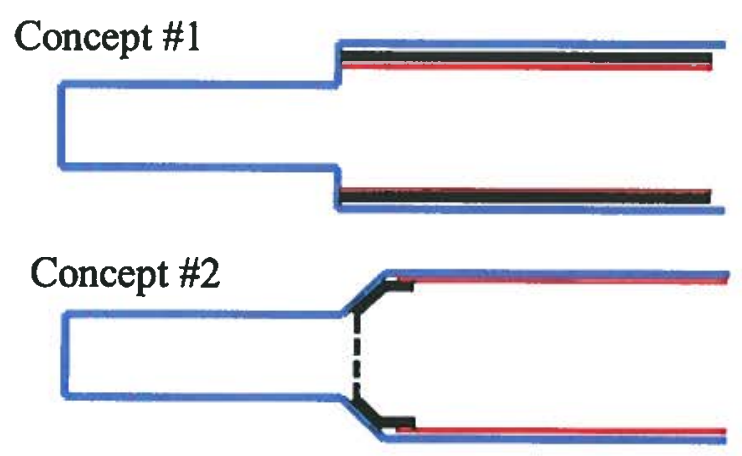

Vacuum Chamber
Concept \#3

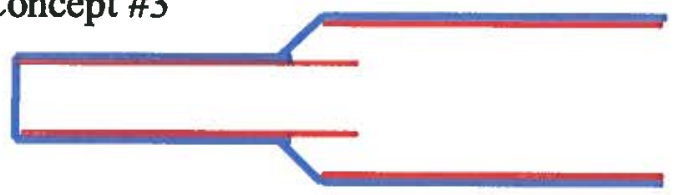

Concept \#4

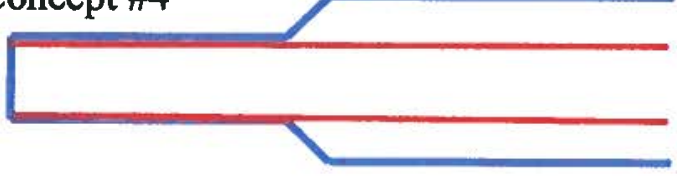

Re-usable Liner Component

Figure 3-4. Comparison of VSD Liner Concepts

Liner Concept \#1 was similar to the one previously tested ${ }^{[4]}$ with the exception that a disposable 0.015-in liner was placed on the inside of the removable liner (Figure 3-5). Both liners were fabricated from $304 \mathrm{~L}$ stainless steel. Inside the disposable liner were placed baffles, also fabricated from 304L stainless steel. The baffles serve as a heat shield between the heated and cooled zones; they also direct gas flows to the walls of the liner to facilitate salt deposition in the liner. The removable liner had a 9-cm outside diameter (OD) with rails on the outside to center the liner inside the $10-\mathrm{cm}$ ID of the vacuum chamber. The disposable liner fit inside the removable liner. An end cap prevented salt from getting in between the two liners. 

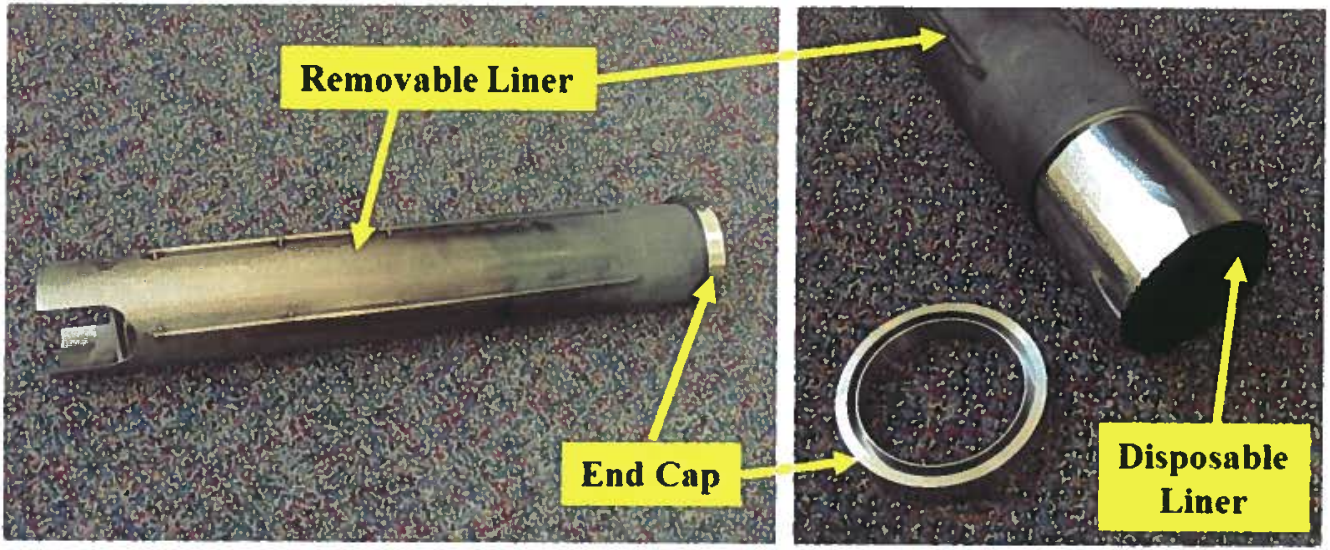

Figure 3-5. Removable Liner Concept with Disposable Liner and Re-usable End Cap

Liner Concept \#2 used a disposable liner press fit around a re-usable tapered end cap (Figure 3-6). The tapered end cap, fabricated from Alloy 600, resides in the heated zone of the vacuum chamber so that salts deposit in the liner instead of on the end cap. The taper of the end cap is designed to match the taper of the vacuum chamber. The length of the disposable liner was varied so that in some tests the liner was pressed against the taper of the vacuum chamber when the door closed; in other tests, there was not a press fit.
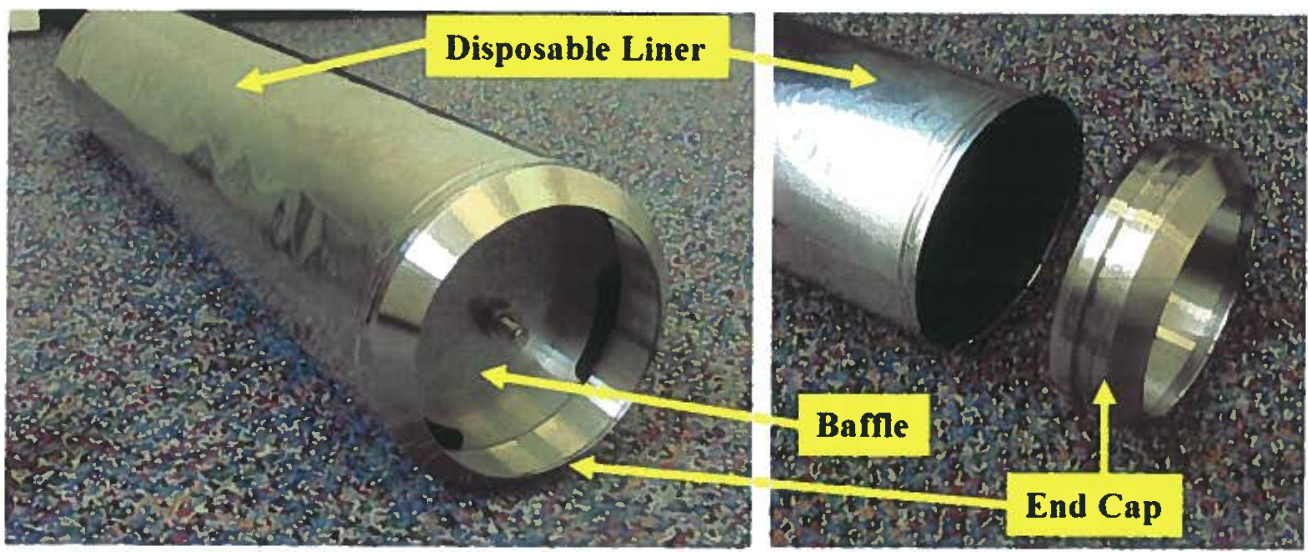

Figure 3-6. Disposable Liner with Re-usable Tapered End Cap

Liner Concept \#3 included a disposable liner in both the heated and cooled sections of the vacuum chamber. Both disposable liners were fabricated from 0.015 -in stainless steel sheet and were made to fit just inside the vacuum chamber. The liner in the heated section was made approximately two inches longer than the smaller-diameter section of the vacuum chamber. The length of the disposable liner in the larger-diameter section was varied so that in some tests the liner was pressed against the taper of the vacuum chamber when the door closed; in other tests, there was not a press fit.

Liner Concept \#4 tested a single-diameter disposable liner that ran from the sealed end of the vacuum chamber to the chamber door.

Small-scale tests used either quartz or alumina boats with a quartz or alumina cover. The smallscale boats were nominally $12 \mathrm{~cm}$ long, $2.5 \mathrm{~cm}$ wide and $2 \mathrm{~cm}$ deep. Pilot-scale boats employed a two-piece lid design to create a tortuous path for any entrained oxide in the halide vapor phase 
to leave the boat. The pilot-scale boat is a $26.5-\mathrm{cm}$ long, $6.5-\mathrm{cm}$ wide boat fabricated from Alloy 600 by the SRNL Machine Shop (Figure 3-7). The boat has a semi-octagonal cross section to provide a stable base.

The pilot-scale boat is similar to the design used in HB-Line with minor variations. The pilotscale boat contains two holes (one in each lid) compared to the HB-Line boat which contains three holes (two in the middle lid and one in the top lid). Previous testing showed that the variation in the lid design will not affect performance. ${ }^{[1]}$ Also, the boat is about $2.5 \mathrm{~cm}$ shorter to provide a design better suited for the heating profile measured in the HB-Line furnace. ${ }^{[12]}$

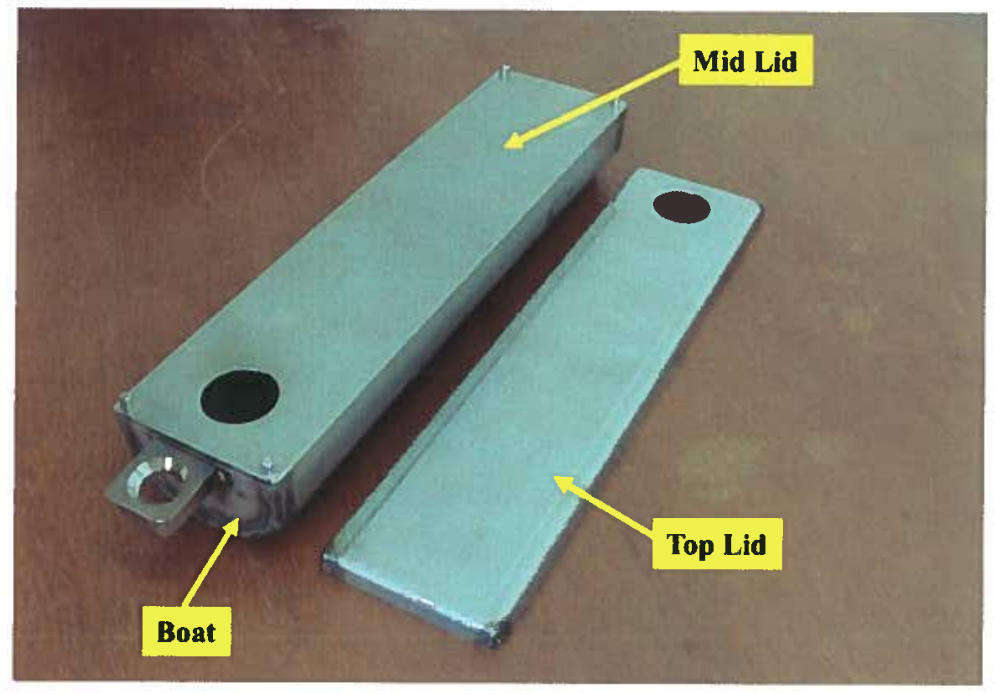

Figure 3-7. Pilot-Scale Feed Boat

\subsection{Test Methods}

\subsubsection{Small-Scale Process Demonstration}

Small-scale demonstrations were completed in the small-scale VSD unit using small quartz or alumina crucibles. Each test started with mixtures of varying amounts of $\mathrm{CeO}_{2}$ (as a surrogate for $\mathrm{PuO}_{2}$ ), $\mathrm{CaCl}_{2}, \mathrm{CaF}_{2}, \mathrm{CeF}_{3}$ (as a surrogate for $\mathrm{PuF}_{3}$ ), sodium chloride $(\mathrm{NaCl}$ ), and potassium chloride $(\mathrm{KCl})$ as the feed added to the crucible. Potassium hydroxide was added to the crucible, and distributed in the feed with a spatula for about a minute. It is expected that this method of mixing introduces a significant amount of variation; however, previous data indicate that the method of mixing is not critical. ${ }^{[4]}$ While mixing is important, the specific of the mixing method do not have to be tightly controlled. The objective is a general distribution of $\mathrm{KOH}$ throughout the feed.

The amount of $\mathrm{KOH}$ was calculated based on the mole ratios of reaction 1 plus varying amounts of excess $\mathrm{KOH}$. The process conditions for the small-scale tests are provided in Table 3-1 and Table 3-2 (shaded cells [Tests 29-41] contain the process conditions for pilot-scale testing). The feed boat was placed in the vacuum chamber and processed according to the heat-cycle information in Table 3-1 and Table 3-2. The cooled-section of the chamber was cooled using $15^{\circ} \mathrm{C}$ water that was supplied from a Lauda E200 closed-loop recirculating bath. 


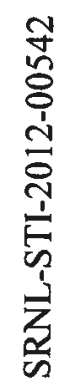

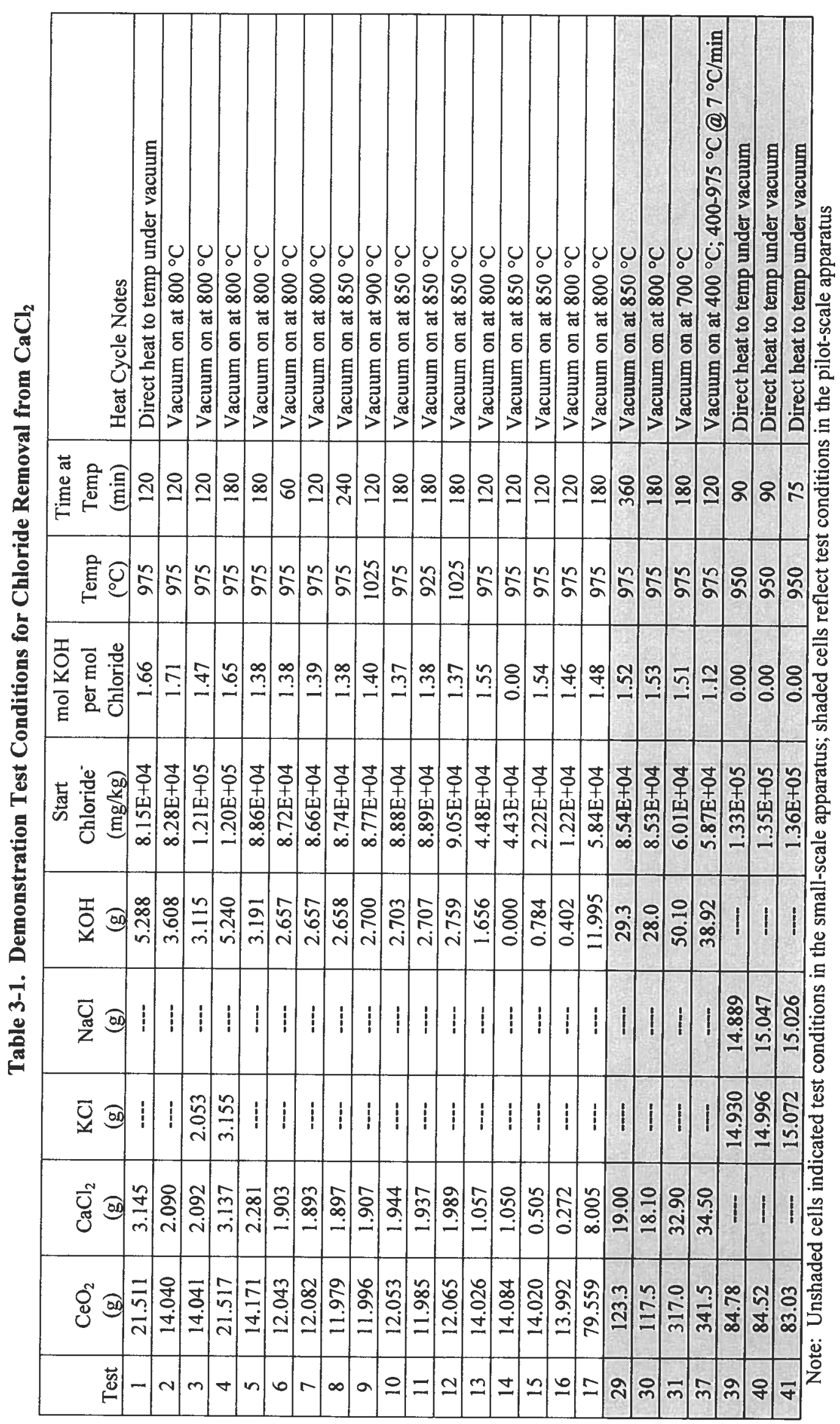


苳

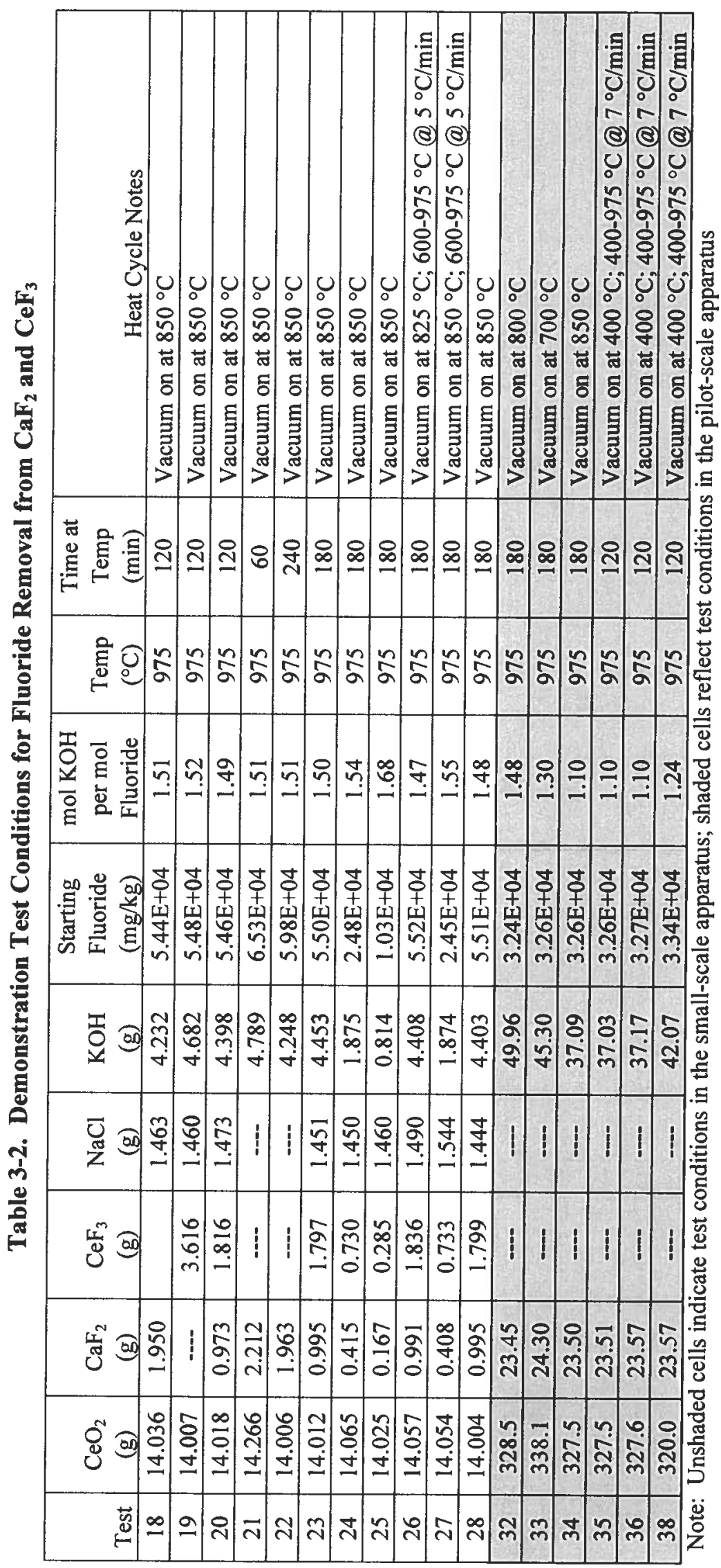


Following the distillation experiment, the concentration of chloride or fluoride in the product boat was measured. The chloride content of the $\mathrm{CeO}_{2}$ was measured as follows. A sample of the distilled oxide was weighed into a plastic centrifuge tube with a screw-on cap. De-ionized (DI) water was added to the centrifuge tube and weighed. The screw cap was secured onto the tube and the tube was shaken vigorously for $3 \mathrm{~min}$. Next, the chloride concentration of the water was tested using a Hach QuanTab ${ }^{\circledR}$ chloride test strip. The fluoride concentration was analyzed by Analytical Development (AD). The sample was digested $(\sim 0.5 \mathrm{~g}$ in $10 \mathrm{~mL}$ of $\sim 1 \mathrm{M}$ sulfuric acid $\left[\mathrm{H}_{2} \mathrm{SO}_{4}\right]$ for $3 \mathrm{~h}$ at $115^{\circ} \mathrm{C}$ ), and the resulting solution analyzed by ion chromatography (IC). Select digested samples were also analyzed by inductively coupled plasma emission spectroscopy (ICPES) for residual potassium.

\subsubsection{Pilot-Scale Process Demonstration}

Pilot-scale demonstrations were completed in the pilot-scale VSD unit using boats with a twopiece lid (see Figure 3-7). Each test started with a selected amount of $\mathrm{CeO}_{2}$ in a stainless steel pan. We then added and mixed into the $\mathrm{CeO}_{2}$ pre-determined amounts of $\mathrm{CaCl}_{2}, \mathrm{CaF}_{2}, \mathrm{NaCl}$, and $\mathrm{KCl}$. Last, $\mathrm{KOH}$ was added to the pan, distributed in the feed (along with the halide salts) with a spatula for about a minute, and then transferred to the feed boat. While distribution of the KOH is important, the specific method of mixing is not critical. A similar effect can be accomplished by combining the feed and $\mathrm{KOH}$ in a plastic bag and mixing the contents by rolling the bag endover-end for about a minute. The objective is a general distribution of $\mathrm{KOH}$ throughout the feed. Intimate solid-solid contact between the $\mathrm{KOH}$ and feed is not required because $\mathrm{KOH}$ will eventually evaporate and be drawn through the feed while exiting the feed boat.

The amount of $\mathrm{KOH}$ was calculated based on the mole ratios of reaction 1 plus a selected molar excess KOH. The masses of reactants for pilot-scale tests [Tests 29-41] are provided in Table 3-1 and Table 3-2. The feed boat was placed in the vacuum chamber and processed according to the heat-cycle information in Table 3-1 and Table 3-2. The cooled-section of the chamber was cooled using either compressed air or $15^{\circ} \mathrm{C}$ water that was supplied from a Lauda E200 closedloop recirculating bath. Following each distillation experiment, the concentration of chloride or fluoride in the product boat was measured using the methods discussed in Section 3.2.1. Select digested samples were also analyzed by ICPES.

\subsubsection{Demonstration with Plutonium Compounds}

Radioactive testing was completed using 3013 DE Item S002250 (Material PS-293), which is fluoride-bearing material that originated in the SRS FB-Line facility. SRNL received $\sim 200 \mathrm{~g}$ of this material. Non-destructive analysis measured the fluoride content at $4.2 \mathrm{wt} \%$ and chloride at $<0.45 \mathrm{wt} \%$. Subsequent sample analysis by digestion followed by IC indicates that the fluoride concentration is $5.14 \mathrm{wt} \%$. Analysis of the material by X-ray diffraction (XRD) indicates that the material is primarily $\mathrm{PuO}_{2}$, with minor amounts of uranyl fluoride hydrate $\left(\mathrm{UO}_{2} \mathrm{~F}_{2}-2 \mathrm{H}_{2} \mathrm{O}\right)$, magnesium fluoride $\left(\mathrm{MgF}_{2}\right)$, nickel oxide $(\mathrm{NiO})$, and nichromite $\left(\mathrm{NiCr}_{2} \mathrm{O}_{4}\right)$. Based on the process mission of the FB-Line facility, it is probable that the uranyl fluoride compound is actually a plutonyl fluoride compound, which would be analogous to the uranyl fluoride compound. The XRD pattern is provided in Figure 3-8.

Demonstrations with Pu compounds were completed in the small-scale VSD unit using a small Alloy 600 boat. Each test started with a known amount of 3013 DE Item S002250. Potassium hydroxide was added, distributed in the feed, and the feed was transferred to the feed boat. For Tests $\mathrm{Pu}-1, \mathrm{Pu}-2 \mathrm{a}$, and $\mathrm{Pu}-2 \mathrm{~b}, \mathrm{KOH}$ was added at $50 \%$ molar excess based on the initial fluoride measurement of $4.2 \mathrm{wt} \%$. The actual molar excess, based on the fluoride analysis of $5.14 \mathrm{wt} \%$, 
was $22 \%$. Adjustments were made for Tests $\mathrm{Pu}-3$ and $\mathrm{Pu}-4$ to achieve a molar excess of $50 \%$ based on $5.14 \mathrm{wt} \%$ fluoride. The masses of reactants are provided in Table 3-3.

The feed boat was placed in the vacuum chamber and processed according to the heat-cycle information in Table 3-3. The cooled-section of the chamber was cooled using $25-50^{\circ} \mathrm{C}$ water that was circulated from a 6-liter reservoir. During Tests $\mathrm{Pu}-1, \mathrm{Pu}-2 \mathrm{a}$, and $\mathrm{Pu}-2 \mathrm{~b}$, issues were encountered with the vacuum pump that prevented the system from reaching the desired vacuum levels $(<0.06$ torr) for sustained periods of time. In light of the results of Test Pu- $2 \mathrm{~b}$ (discussed in Section 4.3), to better understand the impact of time on the rate of fluoride removal, the time at temperature under vacuum was varied incrementally for Tests $\mathrm{Pu}-3 \mathrm{a}$ and $\mathrm{Pu}-3 \mathrm{~b}$.

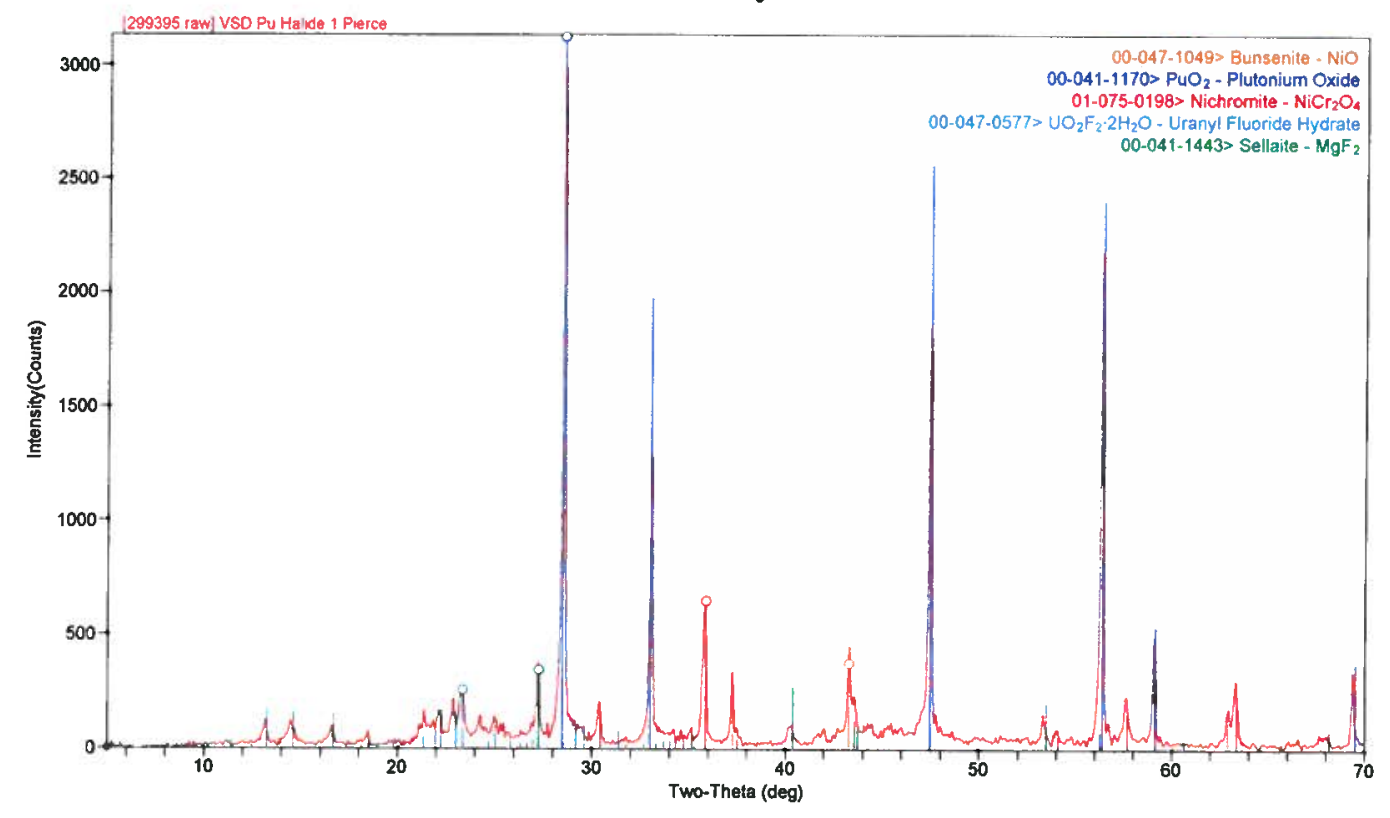

Figure 3-8. XRD Pattern of Pu Material S002250

Table 3-3. Demonstration Test Conditions for Fluoride Removal from S002250

\begin{tabular}{|c|c|c|c|c|c|}
\hline Test & $\begin{array}{l}\text { Temp } \\
\left({ }^{\circ} \mathrm{C}\right)\end{array}$ & $\begin{array}{l}\text { Time at } \\
\text { Temp } \\
\text { (min) }\end{array}$ & $\begin{array}{c}\text { Vacuum } \\
\text { (torr) }\end{array}$ & $\begin{array}{c}\text { Sample } \\
\text { S002250 } \\
\text { (g) }\end{array}$ & $\begin{array}{c}\mathrm{KOH} \\
\text { (g) }\end{array}$ \\
\hline $\mathrm{Pu}-1$ & 975 & 120 & $>5$ & 18.20 & 3.38 \\
\hline $\mathrm{Pu}-2 \mathrm{a}$ & 975 & 120 & $>5$ & 79.79 & 15.16 \\
\hline $\mathrm{Pu}-2 \mathrm{~b}$ & 975 & 15 & 0.06 & \multicolumn{2}{|c|}{ Continue Test $\mathrm{Pu}-2 \mathrm{a}$} \\
\hline $\mathrm{Pu}-3 \mathrm{a}$ & 975 & 35 & 0.06 & 98.98 & 22.40 \\
\hline $\mathrm{Pu}-3 \mathrm{~b}$ & 975 & 65 & 0.06 & \multicolumn{2}{|c|}{ Continue Test $\mathrm{Pu}-3 \mathrm{a}$} \\
\hline
\end{tabular}

After the tests, samples were submitted for analyses. The samples were digested using sodium peroxide fusion followed by dissolution in dilute sulfuric acid. The sulfuric acid solution was then analyzed by IC and ICPES. Some solid product samples were also submitted for XRD for Tests $\mathrm{Pu}-1, \mathrm{Pu}-2 \mathrm{a}$, and $\mathrm{Pu}-2 \mathrm{~b}$. 


\subsection{Results and Discussion}

\subsection{Small-Scale Process Demonstration}

All small-scale tests used $\mathrm{KOH}$ molar excess of $37-70 \%$, with most tests $37-55 \%$ range. Because previous studies indicate better results as the overall product bed depth increased, ${ }^{[4]}$ an evaluation of the impact of $\mathrm{KOH}$ excess was deferred to pilot-scale testing. The matrix of small-scale tests addressed 1) the impact of mixed halides, 2) the impact of $\mathrm{NaCl}$ or $\mathrm{KCl}$ on $\mathrm{KOH}$ requirements, 3) the effect of distillation temperature, 4) the effect of distillation time, and 5) the impact of initial halide concentration on $\mathrm{KOH}$ requirements. The test data are provided in Table 4-1.

Table 4-1. Small-Scale Demonstration Test Results

\begin{tabular}{|c|c|c|c|c|c|c|c|c|}
\hline Test & $\begin{array}{l}\text { Temp } \\
\left({ }^{\circ} \mathrm{C}\right)\end{array}$ & $\begin{array}{l}\text { Time at } \\
\text { Temp } \\
\text { (min) }\end{array}$ & $\begin{array}{l}\mathrm{CeO}_{2} \\
\text { in Feed } \\
(\mathrm{wt} \%) \\
\end{array}$ & $\begin{array}{c}\mathrm{CaCl}_{2} \\
\text { in Feed } \\
\text { (wt \%) }\end{array}$ & $\begin{array}{c}\mathrm{KCl} \\
\text { in Feed } \\
(\mathrm{wt} \%) \\
\end{array}$ & $\begin{array}{c}\mathrm{NaCl} \\
\text { in Feed } \\
(\mathrm{wt} \%)\end{array}$ & $\begin{array}{c}\% \text { Molar } \\
\text { Excess } \\
\text { of } \mathrm{KOH} \\
\end{array}$ & $\begin{array}{r}\text { Product } \\
\text { Chloride } \\
(\mathrm{mg} / \mathrm{kg}) \\
\end{array}$ \\
\hline 1 & 975 & 120 & 87.2 & 12.8 & ---- & $\ldots$ & 66 & $<51$ \\
\hline 2 & 975 & 120 & 87.0 & 13.0 & $-\cdots-$ & $\ldots-$ & 71 & $<30$ \\
\hline 3 & 975 & 120 & 77.2 & 11.5 & 11.3 & $\cdots$ & 47 & $<26$ \\
\hline 4 & 975 & 180 & 77.4 & 11.3 & 11.3 & $\ldots$ & 65 & $<23$ \\
\hline 5 & 975 & 180 & 86.1 & 13.9 & ---- & $\ldots$ & 38 & $<27$ \\
\hline 6 & 975 & 60 & 86.4 & 13.6 & $\ldots$ & $-\cdots$ & 38 & 1079 \\
\hline 7 & 975 & 120 & 86.5 & 13.5 & $\ldots$ & $\cdots$ & 39 & $<34$ \\
\hline 8 & 975 & 240 & 86.3 & 13.7 & $\ldots$ & ---. & 38 & $<38$ \\
\hline 9 & 1025 & 120 & 86.3 & 13.7 & $\ldots$ & $-\cdots$ & 40 & $<39$ \\
\hline 10 & 975 & 180 & 86.1 & 13.9 & $\cdots$ & $\ldots$ & 37 & $<15$ \\
\hline 11 & 925 & 180 & 86.1 & 13.9 & $\ldots$ & $-\cdots$ & 38 & 2337 \\
\hline 12 & 1025 & 180 & 85.9 & 14.1 & $\ldots$ & --.- & 37 & $<21$ \\
\hline 13 & 975 & 120 & 93.0 & 7.0 & $\ldots$ & $-\cdots$ & 55 & $<21$ \\
\hline 14 & 975 & 120 & 93.1 & 6.9 & $\ldots$ & $-\ldots$ & No $\mathrm{KOH}$ & 8500 \\
\hline 15 & 975 & 120 & 96.5 & 3.5 & $-\cdots$ & $-\cdots$ & 54 & 263 \\
\hline 16 & 975 & 120 & 98.1 & 1.9 & $\cdots$ & $\cdots$ & 46 & 78 \\
\hline 17 & 975 & 180 & 90.9 & 9.1 & $-\cdots$ & $\ldots$ & 48 & 206 \\
\hline
\end{tabular}

\begin{tabular}{|c|c|c|c|c|c|c|c|c|}
\hline Test & $\begin{array}{c}\text { Temp } \\
\left({ }^{\circ} \mathrm{C}\right)\end{array}$ & $\begin{array}{c}\text { Time at } \\
\text { Temp } \\
(\mathrm{min})\end{array}$ & $\begin{array}{c}\mathrm{CeO}_{2} \\
\text { in Feed } \\
(\mathrm{wt} \%)\end{array}$ & $\begin{array}{c}\mathrm{CaF}_{2} \\
\text { in Feed } \\
(\mathrm{wt} \%)\end{array}$ & $\begin{array}{c}\mathrm{CeF}_{3} \\
\text { in Feed } \\
(\mathrm{wt} \%)\end{array}$ & $\begin{array}{c}\mathrm{NaCl} \\
\text { in Feed } \\
(\mathrm{wt} \%)\end{array}$ & $\begin{array}{c}\text { \% Molar } \\
\text { Excess } \\
\text { of KOH }\end{array}$ & $\begin{array}{c}\text { Product } \\
\text { Fluoride } \\
(\mathrm{mg} / \mathrm{kg})\end{array}$ \\
\hline 18 & 975 & 120 & 80.4 & 11.2 & 0.0 & 8.4 & 51 & 2099 \\
\hline 19 & 975 & 120 & 73.4 & ---- & 18.9 & 7.6 & 52 & 1697 \\
\hline 20 & 975 & 120 & 76.7 & 5.3 & 9.9 & 8.1 & 49 & 2546 \\
\hline 21 & 975 & 60 & 86.6 & 13.4 & --- & --- & 51 & 2300 \\
\hline 22 & 975 & 240 & 87.7 & 12.3 & --- & --- & 51 & 423 \\
\hline 23 & 975 & 180 & 76.8 & 5.4 & 9.8 & 7.9 & 50 & 300 \\
\hline 24 & 975 & 180 & 84.4 & 2.5 & 4.4 & 8.7 & 54 & 210 \\
\hline 25 & 975 & 180 & 88.0 & 1.0 & 1.8 & 9.2 & 68 & 248 \\
\hline 26 & 975 & 180 & 76.5 & 5.4 & 10.0 & 8.1 & 47 & 533 \\
\hline 27 & 975 & 180 & 84.0 & 2.4 & 4.4 & 9.2 & 55 & 765 \\
\hline 28 & 975 & 180 & 76.8 & 5.5 & 9.9 & 7.9 & 48 & 1258 \\
\hline
\end{tabular}

The MOX feed specification for fluoride in $\mathrm{PuO}_{2}$ is $250 \mathrm{mg} / \mathrm{kg}^{\left[{ }^{[]]}\right.}$(the specification was $7500 \mathrm{mg} / \mathrm{kg}$ throughout much of the program). Of the impure $\mathrm{PuO}_{2}$ materials in storage that do 
not meet the MOX specification because of fluoride contamination, all have fluoride concentrations below $4.5 \mathrm{wt} \%$ (or $45,000 \mathrm{mg} / \mathrm{kg}$ ). Consequently, most of the fluoride removal tests were conducted on $\mathrm{CeO}_{2}$ combined with 4.5-5.5 wt \% fluoride as $\mathrm{CaF}_{2}$. When $\mathrm{CaCl}_{2}$ was used instead of $\mathrm{CaF}_{2}$ because of the ability to immediately analyze for chloride, tests were performed at a nominal chloride concentration of $8.4 \mathrm{wt} \%$. On a mole percent basis, $4.5 \mathrm{wt} \%$ fluoride and $8.4 \mathrm{wt} \%$ chloride yield the same molar concentration of halide.

The data in Table 4-1 address all of the issues stated above. Most important, Table 4-1 shows that all tests with at least $37 \%$ molar excess of $\mathrm{KOH}$ met the initial MOX feed specification for halide, and many achieved $250 \mathrm{mg} / \mathrm{kg}$. Only Test 14 , which had no $\mathrm{KOH}$, yielded a halide concentration in excess of $7500 \mathrm{mg} / \mathrm{kg}$. The data include tests with $\mathrm{CaCl}_{2}, \mathrm{CaF}_{2}, \mathrm{CeF}_{3}$, and $\mathrm{CaF}_{2} / \mathrm{CeF}_{3}$. Mixtures of halides did not impact the ability to meet the specification. Based on a comparison of the top half of Table 4-1 (Tests 1-17) with the bottom half (Tests 18-28), chloride salts distilled more readily than fluoride salts. This result is expected based on the data in Figure 2-2.

The favorable results of Table 4-1 include non-optimal heating cycles. For the tests with $\mathrm{CaCl}_{2}$ (Tests 1-17), the two worst results (excluding Test 14 with no $\mathrm{KOH}$ ) were Test 11 , heated only to $925^{\circ} \mathrm{C}$, and Test 6 , heated at $975^{\circ} \mathrm{C}$ for only $60 \mathrm{~min}$. A similar trend can be seen in the fluoride data. The data for Tests 18-21, at temperature for 60-120 min, are consistently below tests at temperature for at least $180 \mathrm{~min}$. In light of the revised feed specification for halide, a cycle time of $180 \mathrm{~min}$ appears necessary.

A question was raised whether the presence of $\mathrm{NaCl}$ or $\mathrm{KCl}$ with $\mathrm{CaCl}_{2}$ or $\mathrm{CaF}_{2}$ would impact results by consuming some of the $\mathrm{KOH}$, thereby requiring higher amounts of $\mathrm{KOH}$. Prior studies with sodium peroxide fusion showed that sodium peroxide did not react with $\mathrm{KCl}$ or $\mathrm{NaCl}$, but did react with $\mathrm{CaCl}_{2}$, magnesium chloride $\left(\mathrm{MgCl}_{2}\right)$, and neodymium chloride $\left(\mathrm{NdCl}_{3}\right)$. ${ }^{[10]}$ Consistent with the results for sodium peroxide reactions, the presence of $\mathrm{NaCl}$ or $\mathrm{KCl}$ did not increase the quantity of $\mathrm{KOH}$ required for effective distillation of halide. This can be seen best in Tests 18-28 with $\mathrm{CaF}_{2} / \mathrm{CeF}_{3}$ in the feed.

The data in Table 4-1 do not show any significant impact from diminishing concentration of initial fluoride or chloride. The concern was that as initial halide decreases, the amount of initial $\mathrm{KOH}$ would also decreases. Would there be a $\mathrm{KOH}$ quantity that was too small to facilitate effective removal of halide? Tests $12-16$ for $\mathrm{CaCl}_{2}$ and Tests $23-27$ for $\mathrm{CaF}_{2} / \mathrm{CeF}_{3}$ show no impact of reduced concentration of initial halide and $\mathrm{KOH}$. It is worth noting that in Tests 23-27, as the initial halide and $\mathrm{KOH}$ decreased, the amount of $\mathrm{NaCl}$ remained constant without impacting the distillation of halide. The testing of lower initial concentration of halide was unnecessary as those concentrations of halide would already meet the MOX feed specification.

\subsection{Pilot-Scale Process Demonstration}

The scope of testing for the pilot-scale studies was much more limited than the small-scale tests. The results from small-scale testing allowed for the selection of conditions that would most likely represent those deployed in HB-Line. Pilot-scale work studied the impact of the percent molar excess of KOH. The test data are listed in Table 4-2. Pilot-scale testing also evaluated the difference between heating cycles of $120 \mathrm{~min}$ and $180 \mathrm{~min}$.

As expected, the percentage molar excess of $\mathrm{KOH}$ affects the concentration of residual halide in the product. For tests with $\mathrm{CaCl}_{2}$, the removal of halide below $7500 \mathrm{mg} / \mathrm{kg}$ was accomplished even at only $12 \%$ molar excess; removal below $250 \mathrm{mg} / \mathrm{kg}$ occurred at $50 \%$ molar excess. For tests with $\mathrm{CaF}_{2}$, the $\mathrm{MOX}$ specification (within $10 \%$ analytical uncertainty) was not met for both 
experiments at $10 \%$ molar excess $\mathrm{KOH}$ for $120 \mathrm{~min}$ at temperature. However, the specification was achieved for $10 \%$ molar excess $\mathrm{KOH}$ when the system was held at temperature for $180 \mathrm{~min}$. When $30 \%$ molar excess $\mathrm{KOH}$ was added to the feed material, the fluoride concentration was reduced to below the method detection limit of $\sim 250-300 \mathrm{mg} / \mathrm{kg}$.

Table 4-2. Pilot-Scale Demonstration Test Results

\begin{tabular}{|c|c|c|c|c|c|c|c|}
\hline Test & $\begin{array}{c}\text { Temp } \\
\left({ }^{\circ} \mathrm{C}\right)\end{array}$ & $\begin{array}{c}\text { Time at } \\
\text { Temp } \\
(\mathrm{min})\end{array}$ & $\begin{array}{c}\mathrm{CeO}_{2} \\
\text { in Feed } \\
(\mathrm{wt} \%)\end{array}$ & $\begin{array}{c}\mathrm{CaCl}_{2} \\
\text { in Feed } \\
(\mathrm{wt} \%)\end{array}$ & $\begin{array}{c}\text { Chloride } \\
\text { in Feed } \\
(\mathrm{wt} \%)\end{array}$ & $\begin{array}{c}\% \text { Molar } \\
\text { Excess } \\
\text { of KOH }\end{array}$ & $\begin{array}{c}\text { Product } \\
\text { Chloride } \\
(\mathrm{mg} / \mathrm{kg})\end{array}$ \\
\hline 29 & 975 & 360 & 86.6 & 13.4 & 8.54 & 52 & $<28$ \\
\hline 30 & 975 & 180 & 86.7 & 13.3 & 8.53 & 53 & $<21$ \\
\hline 31 & 975 & 180 & 90.6 & 9.4 & 6.01 & 51 & $<240$ \\
\hline 37 & 975 & 120 & 90.8 & 9.2 & 5.87 & 12 & 2339 \\
\hline
\end{tabular}

\begin{tabular}{|c|c|c|c|c|c|c|c|}
\hline Test & $\begin{array}{c}\text { Temp } \\
\left({ }^{\circ} \mathrm{C}\right)\end{array}$ & $\begin{array}{c}\text { Time at } \\
\text { Temp } \\
(\mathrm{min})\end{array}$ & $\begin{array}{c}\mathrm{CeO}_{2} \\
\text { in Feed } \\
(\mathrm{wt} \%)\end{array}$ & $\begin{array}{c}\mathrm{CaF}_{2} \\
\text { in Feed } \\
(\mathrm{wt} \%)\end{array}$ & $\begin{array}{c}\text { Fluoride } \\
\text { in Feed } \\
(\mathrm{wt} \%)\end{array}$ & $\begin{array}{c}\% \text { Molar } \\
\text { Excess } \\
\text { of KOH }\end{array}$ & $\begin{array}{c}\text { Product } \\
\text { Fluoride } \\
(\mathrm{mg} / \mathrm{kg})\end{array}$ \\
\hline 32 & 975 & 180 & 93.3 & 6.7 & 3.24 & 48 & $<232$ \\
\hline 33 & 975 & 180 & 93.3 & 6.7 & 3.26 & 30 & $<292$ \\
\hline 34 & 975 & 180 & 93.3 & 6.7 & 3.26 & 10 & 3989 \\
\hline 35 & 975 & 120 & 93.3 & 6.7 & 3.26 & 10 & 6657 \\
\hline 36 & 975 & 120 & 93.3 & 6.7 & 3.27 & 10 & 7206 \\
\hline 38 & 975 & 120 & 93.1 & 6.9 & 3.34 & 24 & 2700 \\
\hline
\end{tabular}

The importance of reducing the residual $\mathrm{KOH}$ extends beyond process optimization. Empirical observations of the post-distillation products show that increases in the concentration of $\mathrm{KOH}$ increase the degree to which the product particles stick together and form clumps. When a nominal $50 \%$ molar excess of $\mathrm{KOH}$ is used, the product requires some grinding to form a powder. When a nominal excess of $20-30 \%$ molar excess of $\mathrm{KOH}$ is employed, the product readily crumbles when a small amount of force is applied. Even at $10 \%$ molar excess, the product holds a shape, but reverts to a powder form readily. This is in contrast with the distillation of $\mathrm{NaCl}$ and $\mathrm{KCl}$ from $\mathrm{CeO}_{2}$ in which the product was a loose powder. Consequently, $\mathrm{KOH}$ additions should be minimized.

Samples of the pilot-scale test products were dissolved and analyzed for by ICPES to determine if there is a measurable increase in the amount of residual $\mathrm{K}$ as a function of increasing molar excess of KOH. It is important to remember that the same material was re-used for Tests 31-38 (see Table 4-3).

Potassium data indicate that the use of $50 \%$ molar excess $\mathrm{KOH}$ (Tests 31 and 32) leads to increases in residual $\mathrm{K}$, even when heated for $180 \mathrm{~min}$ at temperature. Reducing the amount of molar excess $\mathrm{KOH}$ (Tests 33 and 34) enabled a net reduction in the residual $\mathrm{K}$ when a 180-min heating cycle was used. However, when the heating cycle was decreased to $120 \mathrm{~min}$, even at only $10 \%$ molar excess $\mathrm{KOH}$, the residual $\mathrm{K}$ concentration increased for $\mathrm{CaF}_{2}$ processing but decreased for $\mathrm{CaCl}_{2}$ processing. Consequently, consistent with the fluoride data of Table 4-2, the furnace cycle time for the quantity of material in the boat should be $180 \mathrm{~min}$. The quantity of material in the boat for these tests with $\mathrm{CeO}_{2}$ is comparable to what would be expected for operations with $\mathrm{PuO}_{2}$. It is not clear if a 240 -min furnace cycle would improve $\mathrm{K}$ results, and how it would affect product consistency. 
Table 4-3. Pilot-Scale Potassium Data by ICPES

\begin{tabular}{|c|c|c|c|c|c|c|c|c|}
\hline Test & $\begin{array}{c}\text { Temp } \\
\left({ }^{\circ} \mathrm{C}\right)\end{array}$ & $\begin{array}{c}\text { Time at } \\
\text { Temp } \\
(\mathrm{min})\end{array}$ & $\begin{array}{c}\mathrm{CeO}_{2} \\
\text { in Feed } \\
(\mathrm{wt} \%)\end{array}$ & $\begin{array}{c}\mathrm{CaCl}_{2} \\
\text { in Feed } \\
(\mathrm{wt} \%)\end{array}$ & $\begin{array}{c}\mathrm{CaF}_{2} \\
\text { in Feed } \\
(\mathrm{wt} \%)\end{array}$ & $\begin{array}{c}\% \text { Molar } \\
\text { Excess } \\
\text { of } \mathrm{KOH}\end{array}$ & $\begin{array}{c}\mathrm{K} \text { by } \\
\text { ICPES } \\
(\mathrm{mg} / \mathrm{kg})\end{array}$ & $\begin{array}{c}\Delta \mathrm{K} * \\
(\mathrm{mg} / \mathrm{kg})\end{array}$ \\
\hline 31 & 975 & 180 & 90.6 & 9.4 & ---- & 51 & 1427 & +1427 \\
\hline 32 & 975 & 180 & 93.3 & ---- & 6.7 & 48 & 3992 & +2565 \\
\hline 33 & 975 & 180 & 93.3 & ---- & 6.7 & 30 & 3208 & -784 \\
\hline 34 & 975 & 180 & 93.3 & ---- & 6.7 & 10 & 1613 & -1595 \\
\hline 35 & 975 & 120 & 93.3 & ---- & 6.7 & 10 & 2533 & +920 \\
\hline 36 & 975 & 120 & 93.3 & ---- & 6.7 & 10 & 3330 & +797 \\
\hline 37 & 975 & 120 & 90.8 & 9.2 & ---- & 12 & 632 & -2698 \\
\hline 38 & 975 & 120 & 93.1 & ---- & 6.9 & 24 & 2260 & +1628 \\
\hline
\end{tabular}

Empirical observations of the post-VSD product do not indicate a correlation between residual $\mathrm{K}$ and product consistency. This is best illustrated by data for Tests 31,32 , and 36 . The products from Tests 31 and 32 both formed large coagulated chunks that required significant mechanical effort to size-reduce the product back to powder. Conversely, the product from Test 36 was much softer and readily converted back to powder with little mechanical effort. Similar behavior was observed for the products from Tests 34,35 , and 37 . Comparing the $\mathrm{K}$ data for Tests 31 and 32 (Table 4-3) shows that the $\mathrm{K}$ concentration for Test 31 is the lowest in the table and highest for Test 32 , and yet the product consistency was similar for both products. Conversely, the K data for Tests 31 and 36 are comparable, but the product consistency is vastly different.

\subsection{Demonstration with Plutonium Compound}

In previous studies, $\mathrm{SRNL}$ demonstrated fluoride removal from a mixture of $\mathrm{Pu}$ trifluoride $\left(\mathrm{PuF}_{3}\right)$ and $\mathrm{Pu}$ tetrafluoride $\left(\mathrm{PuF}_{4}\right){ }^{[4]}$ This work did not include tests with materials that might be processed in HB-Line. Consequently, material S002250 was obtained for testing in SRNL and potential processing in HB-Line. Approximately $200 \mathrm{~g}$ of the material were shipped to SRNL.

Tests $\mathrm{Pu}-1, \mathrm{Pu}-2 \mathrm{a}$, and $\mathrm{Pu}-2 \mathrm{~b}$ were prepared based on a KAMS (K-Area Material Storage) analysis showing $4.2 \mathrm{wt} \%$ fluoride. However, destructive analysis (dissolution followed by gamma spectroscopy) after Tests $\mathrm{Pu}-1, \mathrm{Pu}-2 \mathrm{a}$, and $\mathrm{Pu}-2 \mathrm{~b}$ revealed that the sample contained $5.14 \mathrm{wt} \%$ fluoride. Consequently, instead of having $50 \%$ molar excess $\mathrm{KOH}$, the tests contained only $21-22 \%$ molar excess. It is not known how this impacted fluoride removal. Adjustments were made for Tests $\mathrm{Pu}-3 \mathrm{a}$ and $\mathrm{Pu}-3 \mathrm{~b}$ to compensate for the higher-than-expected fluoride concentration in the sample.

Analysis of the product by XRD after Test Pu-2b (Figure 4-1) showed no detectable fluoride compounds. Consequently, samples were not submitted for XRD after Tests Pu-3a and Pu-3b. Residual fluoride data for all tests with the S002250 material are listed in Table 4-4. Even under inadequate vacuum (Tests $\mathrm{Pu}-1$ and $\mathrm{Pu}-2 \mathrm{a}$ ), 23-42\% of the fluoride was removed with more fluoride distilling from the small sample (Pu-1) than the large sample (Pu-2a). After only 15 min of acceptable vacuum ( 0.06 torr), fluoride removal from the sample increased from $23 \%$ to $72 \%$.

The data for Tests $\mathrm{Pu}-3 \mathrm{a}$ and $\mathrm{Pu}-3 \mathrm{~b}$ demonstrate the removal of fluoride below the initial MOX specification of $7500 \mathrm{mg} / \mathrm{kg}$. Although, both data points are below the quantitation limits for the method, the IC spectra show a definite decrease in fluoride from $35 \mathrm{~min}$ at vacuum to $65 \mathrm{~min}$ at vacuum, as reported in Table 4-4. The data suggest that for process cycles of 120-180 min, the residual fluoride will be even lower. Although the data for Test $\mathrm{Pu}-2 \mathrm{~b}$ was performed at a 
different percent molar excess of fluoride that Tests $\mathrm{Pu}-3 \mathrm{a}$ and $\mathrm{Pu}-3 \mathrm{~b}$, the data from Table $4-4$ are graphed in Figure 4-2. In light of the updated MOX specification of $250 \mathrm{mg} / \mathrm{kg}$, the data in Figure 4-2 can be extrapolated to show that the updated specification would be achieved in about $90 \mathrm{~min}$. This heating cycle is half of the heating cycle $(180 \mathrm{~min})$ deemed necessary based on the pilot-scale testing.

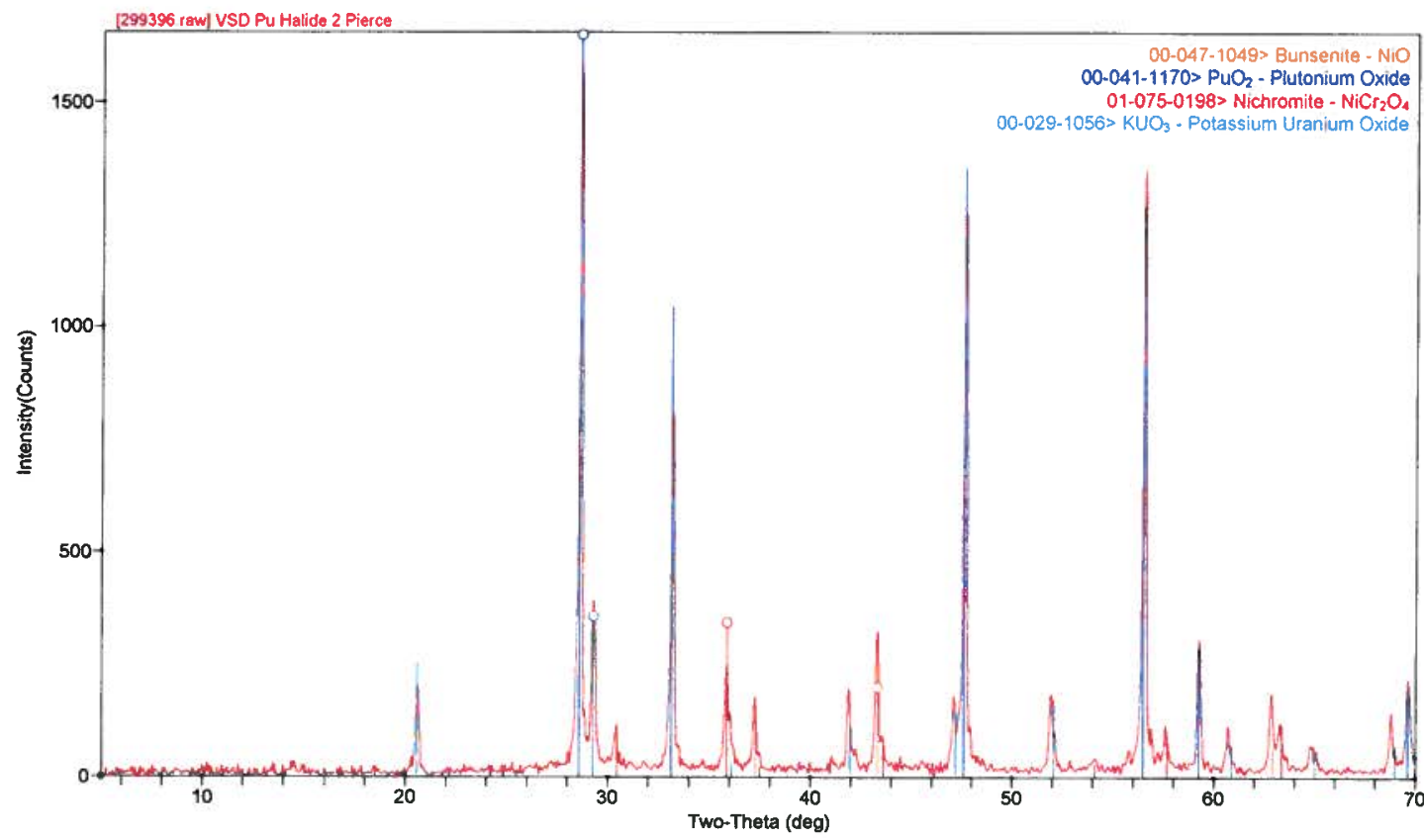

Figure 4-1. S002250 after Reaction with $\mathrm{KOH}$ followed by VSD for $15 \mathrm{~min}$

Table 4-4. Demonstration Test Results for Pu Sample S002250

\begin{tabular}{|c|c|c|c|c|c|c|c|}
\hline Test & $\begin{array}{c}\text { Temp } \\
\left({ }^{\circ} \mathrm{C}\right)\end{array}$ & $\begin{array}{c}\text { Time at } \\
\text { Temp } \\
(\mathrm{min})\end{array}$ & $\begin{array}{c}\text { Vacuum } \\
\text { (torr) }\end{array}$ & $\begin{array}{c}\text { Fluoride } \\
\text { in Feed } \\
(\text { wt \%) }\end{array}$ & $\begin{array}{c}\text { \% Molar } \\
\text { Excess } \\
\text { of KOH }\end{array}$ & $\begin{array}{c}\text { Product } \\
\text { Fluoride } \\
(\mathrm{mg} / \mathrm{kg})\end{array}$ & $\begin{array}{c}\text { \% Fluoride } \\
\text { Removed }\end{array}$ \\
\hline $\mathrm{Pu}-1$ & 975 & 120 & $>5$ & 5.14 & 22 & 29800 & 42 \\
\hline $\mathrm{Pu}-2 \mathrm{a}$ & 975 & 120 & $>5$ & 5.14 & 21 & 39700 & 23 \\
\hline $\mathrm{Pu}-2 \mathrm{~b}$ & 975 & 15 & 0.06 & 5.14 & 21 & 14300 & 72 \\
\hline $\mathrm{Pu}-3 \mathrm{a}$ & 975 & 35 & 0.06 & 5.14 & 49 & $4410^{*}$ & 91 \\
\hline $\mathrm{Pu}-3 \mathrm{~b}$ & 975 & 65 & 0.06 & 5.14 & 49 & $1070^{*}$ & 98 \\
\hline
\end{tabular}

* IC data for Pu-3a (42 mg/L) and Pu-3b (11 mg/L) were below the method quantitation limit of $50 \mathrm{mg} / \mathrm{L}$ 


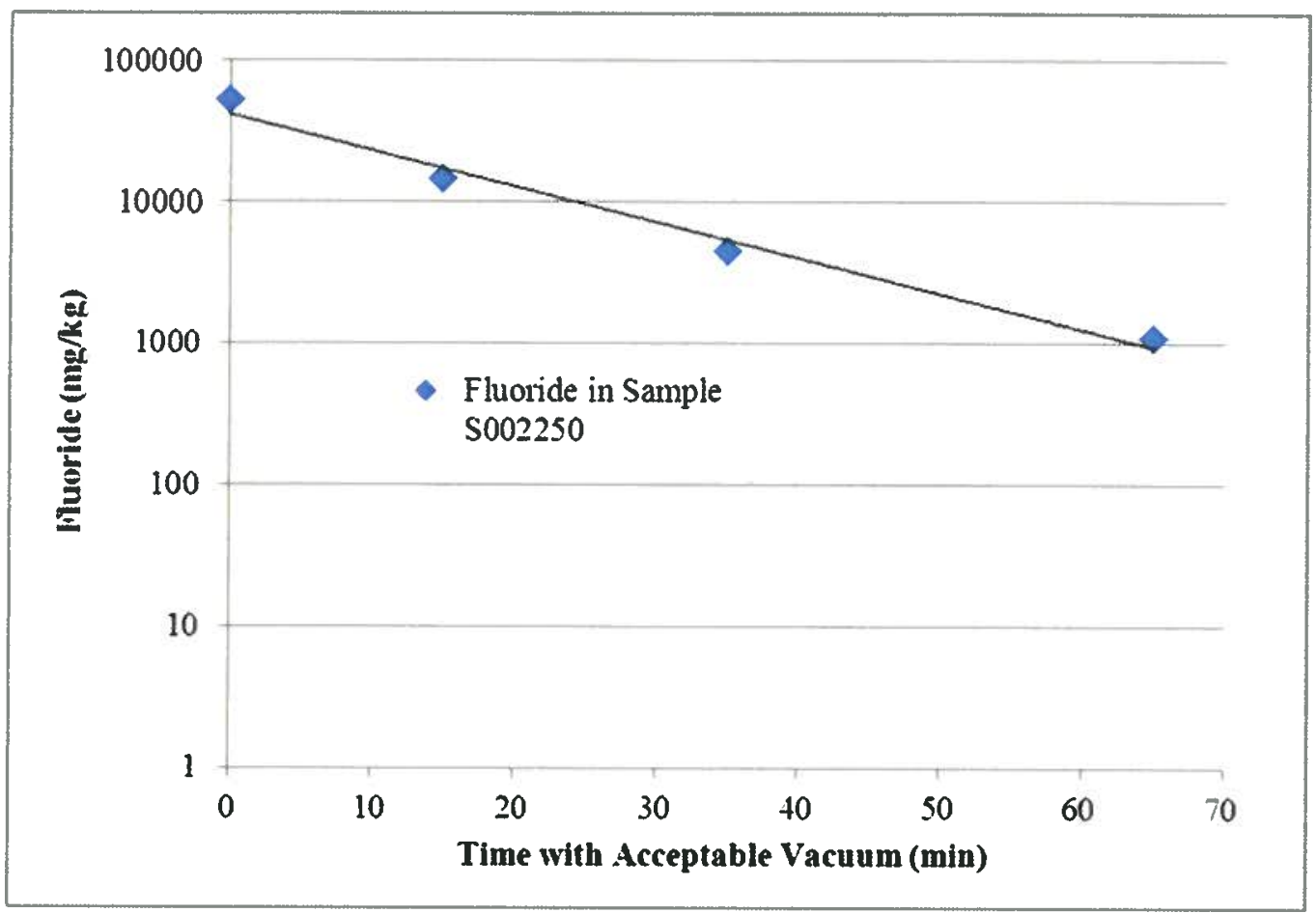

Figure 4-2. Distillation of Fluoride from Sample S002250

\subsection{Removable Liner Design Considerations}

Four liner concepts were tested on the pilot-scale apparatus. Their characteristics are discussed in Section 3.1 and schematically re-presented in Figure 4-3. Concept \#1 was tested as a proof-inconcept design at the end of FY11. It provided the baseline, but was not expected to be the optimal design. A typical salt deposition pattern in the vacuum chamber for Concept \#1 is provided in Figure 4-4. Typical salt deposition in the liner for Concepts 1-3 is shown in Figure 4-5. Due to rapid absorption of moisture by $\mathrm{KOH}$ in air, quantitative measurements of the salt mass in the vacuum chamber were not practical for Tests 31-38. Consequently, judgments are based more on qualitative data, and primarily photographs (see Attachment 1). Although Concept \#1 proved that a removable liner approach was feasible, it provided reason to expect significant improvements with a different design.
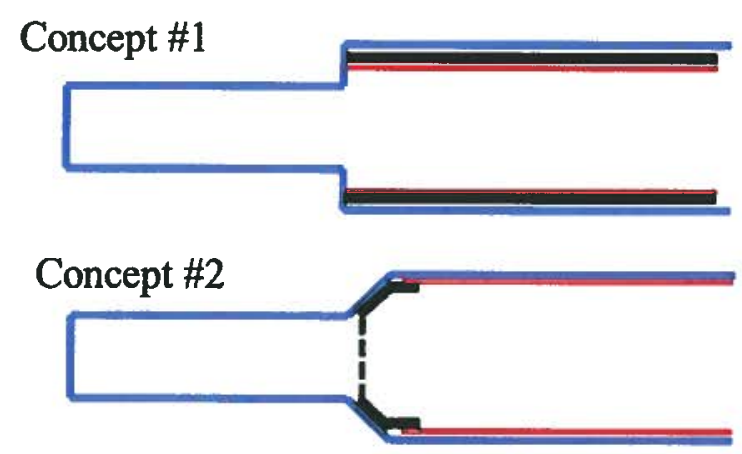

Vacuum Chamber

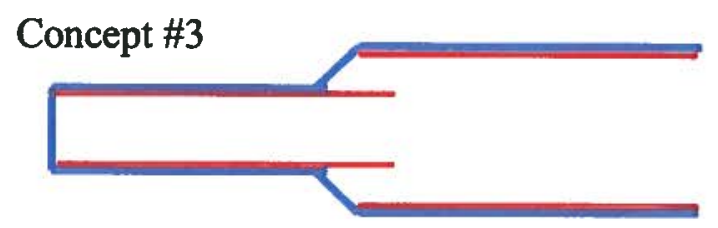

\section{Concept \#4}

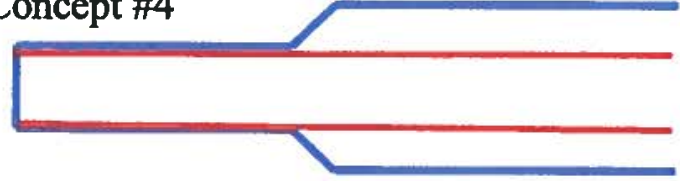

Figure 4-3. Comparison of VSD Liner Concepts 


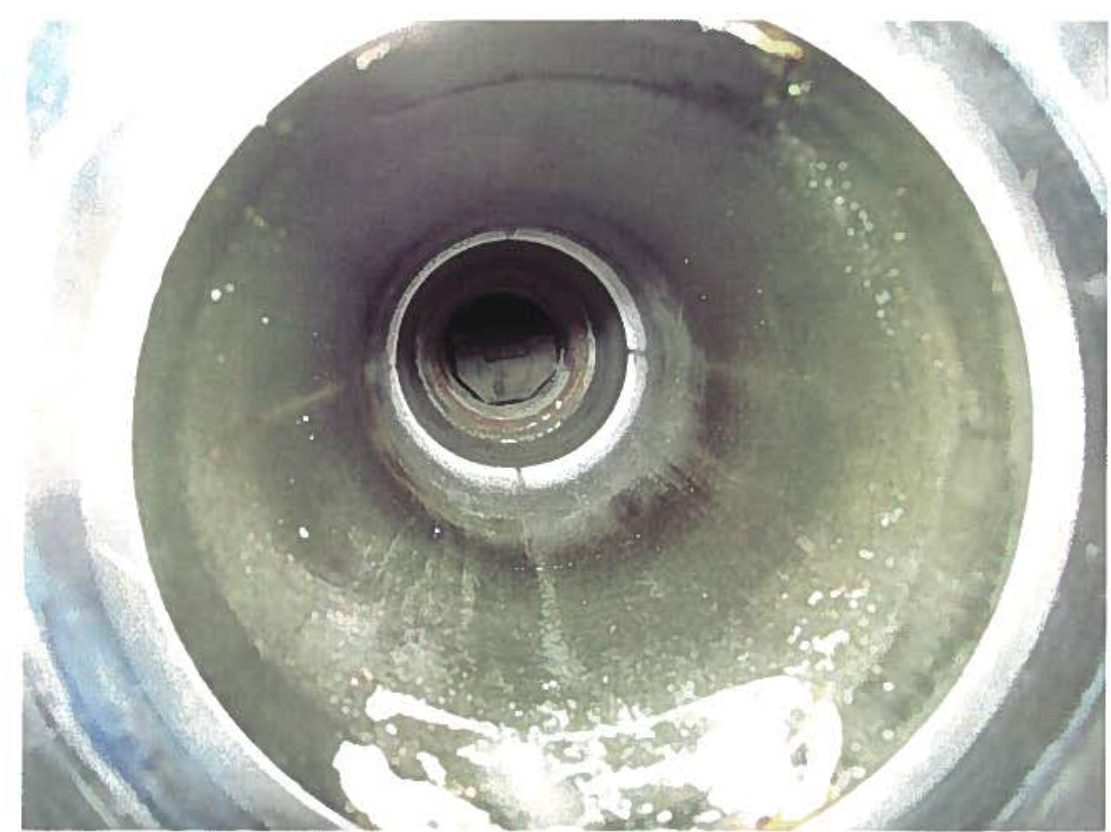

Figure 4-4. Typical Salt Deposition Pattern in Vacuum Chamber - Concept \#1

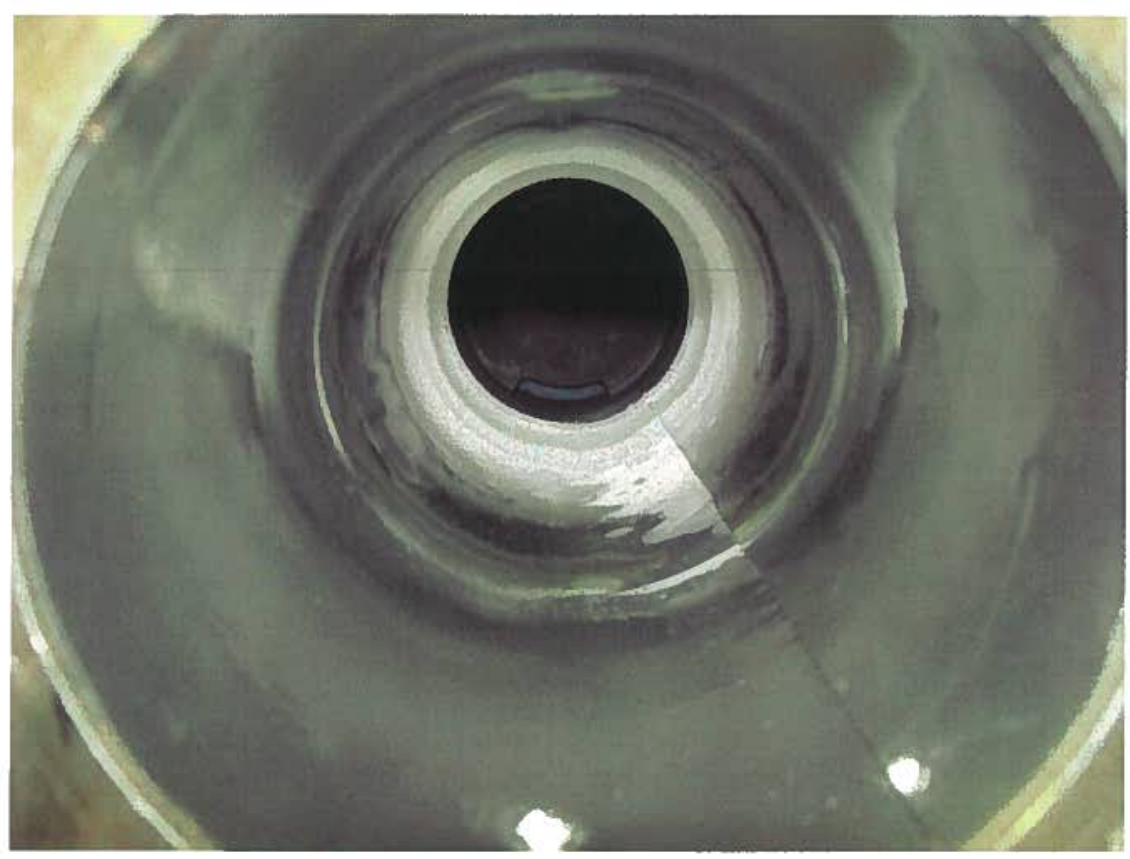

Figure 4-5. Typical Salt Deposition Pattern in Removable Liner

At the outset of FY12, the vacuum chamber was modified to a tapered transition zone to mirror the design of the unit in HB-Line. Inclusion of a taper was also expected to enable optimization of a removable liner concept. Concepts \#2 and \#3 were the primary designs tested. Concept \#4, was dismissed after one test due to adherence of the liner to the vacuum chamber and large quantities of salt on the vacuum chamber wall. Concepts \#2 and \#3 were both tested with the 
liner fit correctly to the chamber length and with the liner slightly longer than the chamber to provide a press fit.

Table 4-5. Removable Liner Test Conditions

\begin{tabular}{|c|c|c|c|c|c|l|}
\hline Test & $\begin{array}{c}\text { Ciner } \\
\text { Concept }\end{array}$ & $\begin{array}{c}\text { Press } \\
\text { Fit } \\
\text { (Y/N) }\end{array}$ & $\begin{array}{c}\text { Vacuum } \\
\text { Pump } \\
\text { Type }\end{array}$ & $\begin{array}{c}\text { Coolant } \\
\text { Type }\end{array}$ & $\begin{array}{c}\text { KOH } \\
\text { Used } \\
\text { Y/N })\end{array}$ & \multicolumn{1}{|c|}{ Observations } \\
\hline 31 & 3 & Y & Oil & Air & Y & Liner difficult to remove \\
\hline 32 & 2 & N & Oil & Air & Y & Liner easy to remove and separate from cap \\
\hline 33 & 2 & Y & Oil & Air & Y & $\begin{array}{l}\text { Liner easy to remove; difficult to separate } \\
\text { from tapered end cap }\end{array}$ \\
\hline 34 & 2 & N & Oil & Air & Y & Liner easy to remove and separate from cap \\
\hline 35 & 2 & Y & Oil & Water & Y & Similar salt content to Test 39; no pictures \\
\hline 36 & 2 & N & Dry & Air & Y & Liner easy to remove \\
\hline 37 & 2 & N & Oil & Air & Y & $\begin{array}{l}\text { Liner binds, likely from accumulation of } \\
\text { salt over several runs }\end{array}$ \\
\hline 38 & 4 & N & Dry & Air & Y & $\begin{array}{l}\text { Liner binds to chamber; large amounts of } \\
\text { salt on vacuum chamber wall }\end{array}$ \\
\hline $39^{*}$ & 2 & N & Oil & Air & N & $\sim 0.01$ g salt \\
\hline $40^{*}$ & 2 & Y & Oil & Air & N & Less salt than Test 39; difficult to quantify \\
\hline $41^{*}$ & 3 & Y & Oil & Air & N & $\sim 0.05$ g salt \\
\hline * Chronologically, Tests 39-41 without KOH were completed before Test 31 \\
\hline
\end{tabular}

A list of the liner trials is shown in Table 4-5. Chronologically, Tests $39-41$ without $\mathrm{KOH}$ were completed before Test 31. Because Tests $39-41$ did not use $\mathrm{KOH}$, it was possible to semiquantitatively measure the salt on the vacuum chamber wall. When $\mathrm{KOH}$ is used, it absorbs moisture readily and thus makes quantitative salt residue measurements difficult. Comparisons of tests using $\mathrm{KOH}$ are based on observations (Table 4-5) and photographs (Attachment 1). Based on issues of salt content and liner removal, Concepts \#1 and \#4 were removed from consideration.

Concepts \#2 and \#3 were compared with consideration of whether the liner was press fit or not. The advantage of Concept \#3 is that it does not involve sliding a liner onto a re-usable end cap in the glovebox. The disadvantages of Concept \#3 are the presence of hot-zone liner and the lack of a good fit in the chamber if it is not press fit. Concept \#2 yields a good fit in the chamber regardless of whether it is press fit or not. Consequently, the liner does not have to be fit close to the vacuum chamber wall.

Concept \#3 with the press fit (Test 31), even though it yielded low quantities of salt deposition, was discarded due to difficulties in removing the liner from the chamber. The press fit distorted the shape of the liner and caused it to catch on the vacuum chamber wall. Concept \#3 without the press fit (Test 41) allowed too much salt to get between the liner and the top half of the vacuum chamber because of the loose fit. The fit could be made tighter, but that would make liner loading and removal more difficult. Therefore, Concept \#3 without a press fit was discarded.

Eight tests were used to compare the performance of Concept \#2 with the press fit (Tests 33, 35, and 40) and without the press fit (Tests 32,34,36,37, and 39). Visually, the quantities of salt residues are similar for both configurations. In no test was the residue completely eliminated. Tests 39 and 40 deposited less than $0.01 \mathrm{~g}$ of salt $(<0.03 \mathrm{wt} \%)$ of the salt outside the liner. Comparing Test 39 with Test 40 indicates that the salt content for the press fit will be slightly less. 
The difference between the two Concept \#2 variations is minor. Using a press fit eliminates the potential for the liner not being seated correctly. However, in Test 33, the press-fit liner was difficult to remove from the tapered end cap. In the HB-Line glovebox, the removal of the liner from the end cap could be more of an issue. A re-design of the end cap should be sufficient to eliminate this difficulty.

An important point to consider is highlighted by Test 37 . Although the quantity of salt outside of the liner was probably minor, the liner was difficult to remove. It is speculated that salt accumulation from several tests, even though it was minor for each test, was sufficient to cause this minor amount of liner adherence to the vacuum chamber wall. Therefore, whichever approach is deployed, there will need to be some form of cleaning of the vacuum chamber wall between process cycles. Polishing the cooled zone with a damp rag after each process cycle should be sufficient to dissolve and remove the salt accumulation.

In light of the various factors, it is recommended that Concept \#2 be employed for the liner with a slight press fit. This approach reduces the potential for operator error in seating the liner. This approach also minimizes the amount of salt that deposits between the liner and the vacuum chamber wall. Minor modifications to the liner and tapered end cap can be developed to eliminate the issue associated with separating the liner from the end cap.

\subsection{Boat Material of Construction}

The vacuum chamber and product boats used Alloy 600 as the material of construction for chloride removal from 3013 DE items in HB-Line. ${ }^{[3]}$ Testing in SRNL showed that an oxide layer accumulated on the boat during the first 3-5 process cycles, and then the surface of the boat changed little thereafter. ${ }^{[11]}$ The addition of $\mathrm{KOH}$ to the system introduces a chemical that is more aggressive in corroding the surfaces of Alloy 600 .

Figure 4-6 depicts the difference between a new Alloy 600 feed boat and one used for 11 process cycles (cycles 39-41 contained no $\mathrm{KOH}$ ). The attack and discoloration of the boat is more pronounced than that observed for VSD without $\mathrm{KOH}$. For the first several tests, tenths of grams of corrosion products were deposited in the material in the boat. However, as with the tests that contained no $\mathrm{KOH}$, the surface passivated with time and the amount of corrosion product deposition diminished. Empirical observations indicate that small amounts of corrosion products are still being deposited with each test, but the amount is not considered problematic from a material stability perspective. However, if the MOX specifications for iron (Fe), nickel (Ni), and chromium $(\mathrm{Cr})$ are restrictive, the use of an alternate boat material may be necessary. 


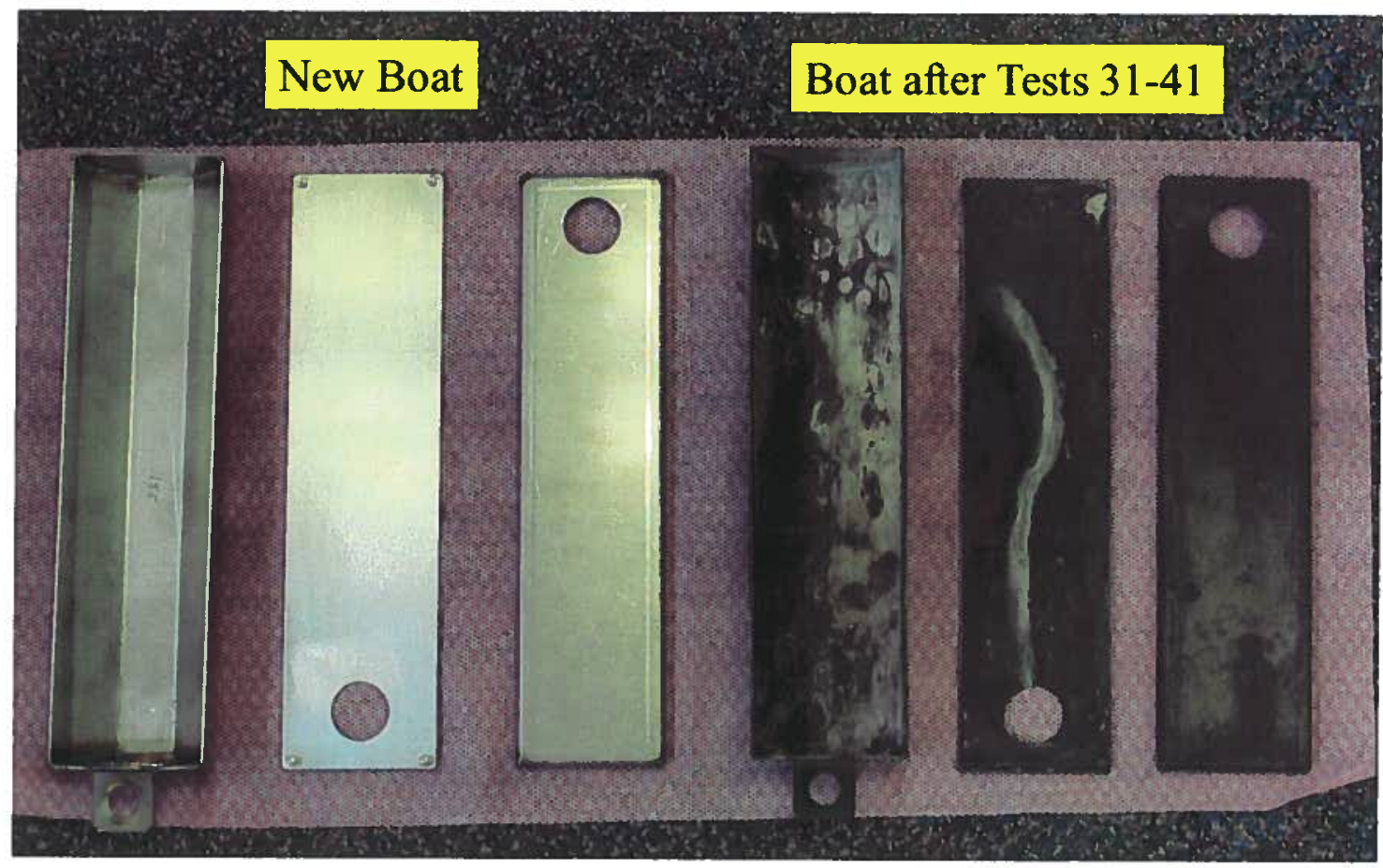

Figure 4-6. Alloy 600 Feed Boat before and after Pilot-Scale Testing

An alternative boat material is alumina, the material used for small-scale testing. Alumina resists attack from both $\mathrm{KOH}$ and sodium peroxide. The availability of intricately-designed boats made from alumina is uncertain. Attempts to identify a vendor have been unsuccessful. A morefeasible approach is to fabricate a simple alumina boat and place it inside an Alloy 600 boat. A simple middle lid could also be fabricated from alumina with the top lid made from Alloy 600 . This approach would greatly limit corrosion product contamination in the boat material.

\subsection{In-Line Moisture Absorption}

As discussed in Section 2.0, the reaction of one mole of $\mathrm{CaF}_{2}$ with two moles of $\mathrm{KOH}$ produces one mole of $\mathrm{H}_{2} \mathrm{O}$. This source of water is a potential issue for the vacuum pumps used to evaporate salts. For an oil pump, like those used for these studies, the water accumulates in the oil and reduces vacuum efficiency. It can be removed by bleeding air through the pump (known as ballasting) while it is operating. For a dry pump, like the one used in HB-Line, the moisture condenses in the pump. The condensate impedes the ability to pull vacuum on the system and can lead to mechanical damage of the pump.

To remove moisture from the gases coming from the vacuum chamber, a column of Drierite ${ }^{\mathrm{TM}}$ (calcium sulfate) was placed between the vacuum chamber and vacuum pump to collect the moisture. The column was $16 \mathrm{~cm}$ long, $2.5 \mathrm{~cm}$ diameter, and contained $112-115 \mathrm{~g}$ of drying media. Pictures of the column before and after testing are shown in Figure 4-7. 


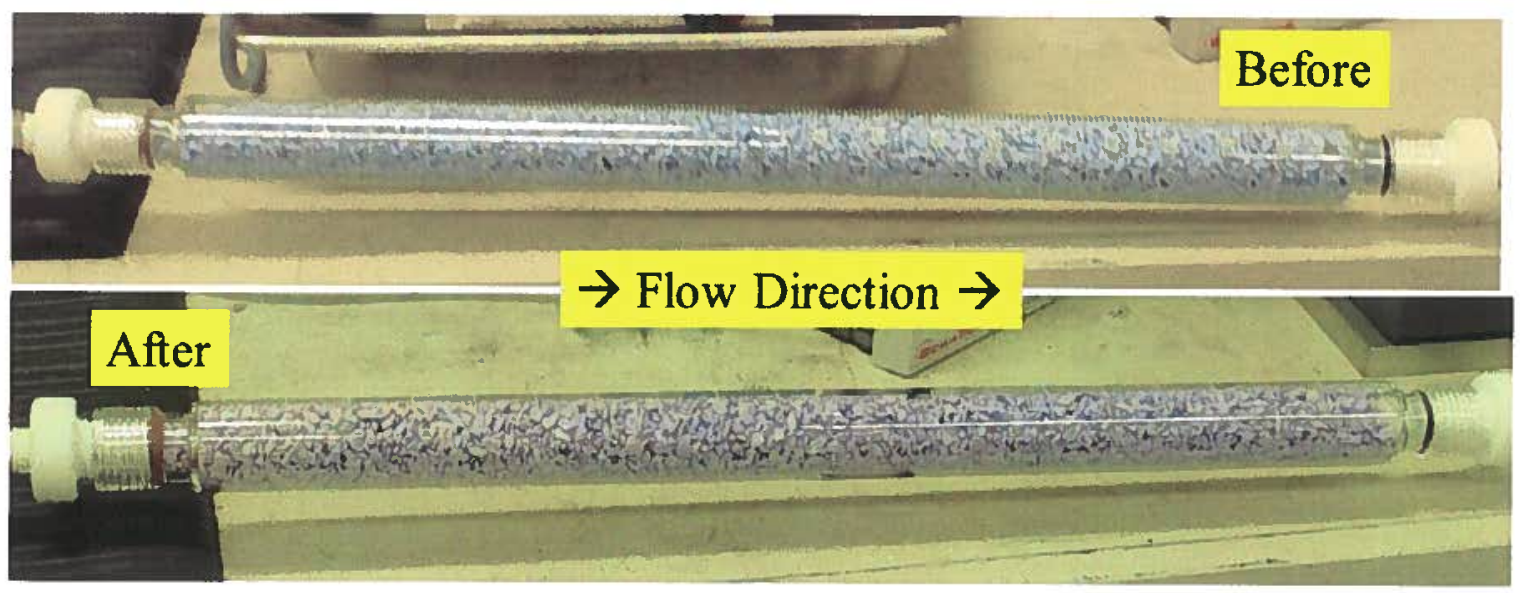

Figure 4-7. Drierite ${ }^{\mathrm{TM}}$ Column for Moisture Absorption Upstream of Vacuum Pump

The column was used for Test $37\left(0.31 \mathrm{~mol} \mathrm{CaCl}_{2}\right)$ and Test $38\left(0.30 \mathrm{~mol} \mathrm{CaF}_{2}\right)$. For Test 37 , the column weight increased $11.26 \mathrm{~g}$; Test 38 increased $11.33 \mathrm{~g}$. Based on Reaction 1, these two values are approximately twice of what was expected for Tests $37(5.60 \mathrm{~g})$ and $38(5.44 \mathrm{~g})$. It is possible that there is another source of water entering the system, either adsorbed by the $\mathrm{CeO}_{2}$ between tests or by the $\mathrm{KOH}$. However, the similarity of the amount of "extra" water in the system for both tests is surprising. An alternate explanation is that one mole of $\mathrm{CaF}_{2}$ reacts with two moles of $\mathrm{KOH}$ by a mechanism different than that of reaction 1 to release two moles of $\mathrm{H}_{2} \mathrm{O}$. Because there are only two data points, the assumption of an extra source of water seems to be the more credible explanation for the difference between the amount of water collected and the amount expected.

It should be noted that Test 37 was performed with an oil vacuum pump (Edwards RV5) and Test 38 was tested with a two-stage dry pump (Alcatel Drytel ${ }^{\mathrm{TM}}$ ). During Test 37, the pump behavior was normal. During Test 38, it was observed that as the system approached the final test temperature, air had to be bled through the pump to remove accumulated moisture. This is consistent with the manner in which the Drytel ${ }^{\mathrm{TM}}$ pump was operated in HB-Line. There did not seem to be "extra" moisture beyond what was observed in prior tests without $\mathrm{KOH}$ addition. The Drierite $^{\mathrm{TM}}$, though, did not remove enough moisture to omit the pump purge step used previously during HB-Line VSD operations.

\subsection{Salt Deposition on the Vacuum Chamber Door}

Testing with $\mathrm{KOH}$ in the feed boat resulted in the deposition of salts on the vacuum chamber door. This was not observed during testing when $\mathrm{KOH}$ was absent from the system. The salt deposition is likely caused by the increased volatility of $\mathrm{KOH}$ when compared to that of $\mathrm{NaCl}$ and $\mathrm{KCl}$ (Figure 2-2). 

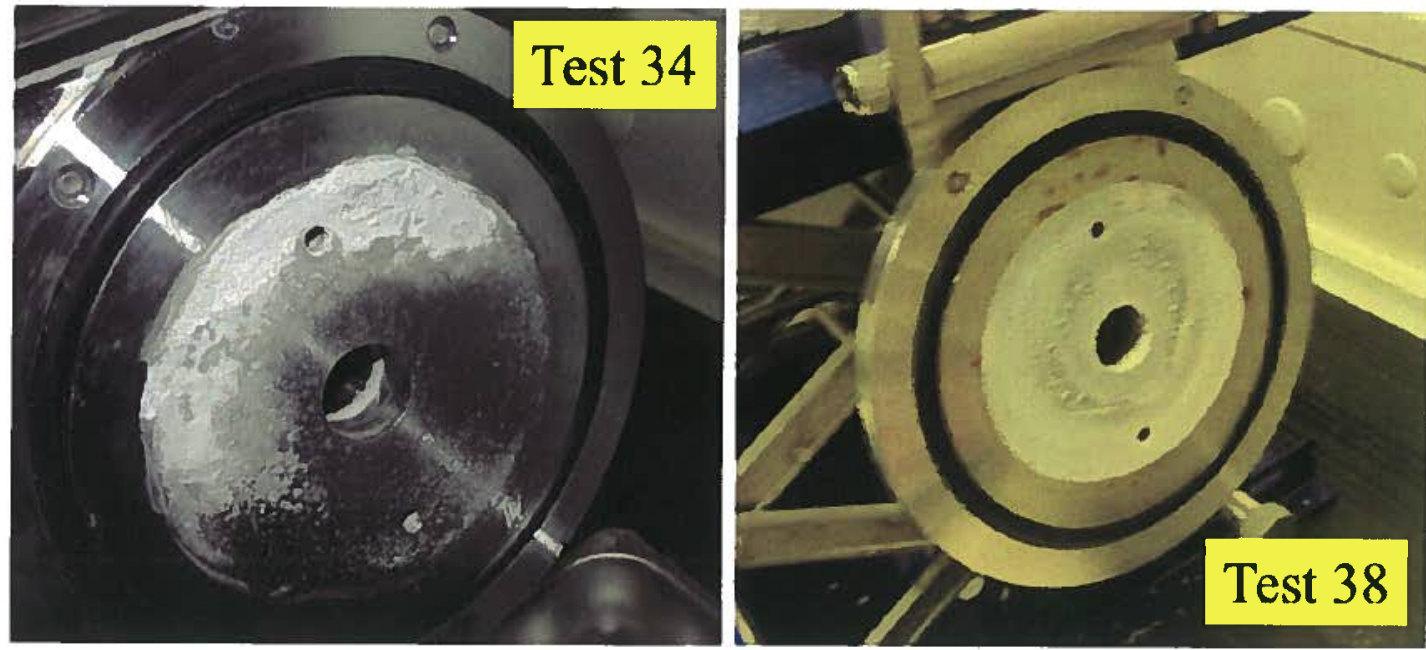

Figure 4-8. Salt Deposition on Vacuum Chamber Door - Tests 34 and 38

Pictures of typical salt deposition from Tests 34 and 38 are shown in Figure 4-8. The picture for Test 34 was taken a few minutes after the door was open. The lack of salt color on the lower half of the door depicts rapid absorption of moisture from the air by the salt. Within 10 minutes, the salt will deliquesce and drip from the door. At the end of Tests 35 and 36, the salt was rinsed from the door with a known quantity of DI water and analyzed for $\mathrm{K}$ to calculate the quantity of $\mathrm{KOH}$ deposited on the door (assuming all $\mathrm{K}$ is $\mathrm{KOH}$ ). Calculations indicate that $0.72 \mathrm{~g}$ and $0.36 \mathrm{~g}$, respectively, were deposited on the door during Tests 35 and 36. Deposition of salt on the door could not be prevented using water cooling of the chamber (Test 35) instead of pressurized air cooling.

In addition to cleaning the salt from the door, the presence of salt on the door poses another issue. This issue is related to safety. The nature of the salt deposition is as a high-surface-area material which is reactive to water. When the material on the door is scraped with a spatula in a moist atmosphere, the material sparks. When the material is contacted with a stream of water (from a squirt bottle), it flares. However, when it has unrestricted contact with the atmosphere, the material absorbs moisture (Figure 4-8) and passivates within several minutes. It is likely that the material can be passivated with the door closed by allowing air into the chamber during system cooling (which takes more than six hours). The concept was validated during Tests 36 and 37, but systematic testing in a configuration comparable to HB-Line has not yet been conducted.

\subsection{Conclusions}

SRNL has successfully demonstrated the removal of halide from $\mathrm{CaCl}_{2}, \mathrm{CaF}_{2}$ and $\mathrm{CeF}_{3}$ below $1000{ }^{\circ} \mathrm{C}$ at the pilot scale using VSD technology. The halides were removed from individual salts and mixtures of them. Potassium hydroxide effectively reacts in situ with $\mathrm{CaCl}_{2}, \mathrm{CaF}_{2}$ and $\mathrm{CeF}_{3}$ to produce $\mathrm{KCl}$ and $\mathrm{KF}$, which can be distilled at an acceptable rate at $1000{ }^{\circ} \mathrm{C}$. Excess $\mathrm{KOH}$ distills with the $\mathrm{KCl}$ and $\mathrm{KF}$. Through a series of non-radioactive studies, SRNL developed a better understanding of the impacts of temperature, time at temperature, concentration of halides, other distilling salts, and excess $\mathrm{KOH}$.

Small-scale testing (20-g scale) consistently removed chloride to less than $100 \mathrm{mg} / \mathrm{kg}$ and fluoride to less than $1000 \mathrm{mg} / \mathrm{kg}$ with $50 \%$ molar excess $\mathrm{KOH}$ and a furnace cycle of $180 \mathrm{~min}$ at $975^{\circ} \mathrm{C}$. This level of halide is below the initial MOX feed specification of $7500 \mathrm{mg} / \mathrm{kg}$. The target was met within $120 \mathrm{~min}$ at $975^{\circ} \mathrm{C}$, but the longer distillation time is recommended. When other distillable salts, such as $\mathrm{KCl}$ or $\mathrm{NaCl}$, were distilled with $\mathrm{CaCl}_{2}, \mathrm{CaF}_{2}$, and $\mathrm{CeF}_{3}$, no 
additional $\mathrm{KOH}$ was required to achieve the MOX specification. Reduction of the initial halide concentration in the feed material, and hence the total amount of $\mathrm{KOH}$ added, did not reduce process effectiveness. The update MOX feed specification of $250 \mathrm{mg} / \mathrm{kg}$ can also be achieved with heating cycles of $975^{\circ} \mathrm{C}$ for $180 \mathrm{~min}$.

Pilot-scale testing (350-g scale) removed chloride and fluoride to less than $250-300 \mathrm{mg} / \mathrm{kg}$ with $30-50 \%$ molar excess $\mathrm{KOH}$ and a furnace cycle of $180 \mathrm{~min}$ at $975{ }^{\circ} \mathrm{C}$. The initial MOX specification was also achieved with $10-20 \%$ molar excess $\mathrm{KOH}$ and a furnace cycle of $180 \mathrm{~min}$ at $975{ }^{\circ} \mathrm{C}$, but with much less margin. A furnace cycle of $120 \mathrm{~min}$ at $975^{\circ} \mathrm{C}$ with $10-12 \%$ molar excess $\mathrm{KOH}$ is inadequate to consistently achieve $7500 \mathrm{mg} / \mathrm{kg}$ residual fluoride, and is unable to achieve the updated MOX specification of $250 \mathrm{mg} / \mathrm{kg}$. The recommended flowsheet entails $30 \%$ molar excess $\mathrm{KOH}$ and a furnace cycle of $180 \mathrm{~min}$ at $975^{\circ} \mathrm{C}$.

The importance of reducing the residual $\mathrm{KOH}$ extends beyond process optimization. Empirical observations of the post-distillation products show that increases in the starting concentration of $\mathrm{KOH}$ increase the degree to which the product particles stick together and form clumps. When a nominal $50 \%$ molar excess of $\mathrm{KOH}$ is used, the post-VSD product requires some grinding to form a powder. When a nominal excess of $20-30 \%$ molar excess of $\mathrm{KOH}$ is employed, the product readily crumbles when a small amount of force is applied. Even at $10 \%$ molar excess, the product holds a shape, but reverts to a powder form readily. This is in contrast with the distillation of $\mathrm{NaCl}$ and $\mathrm{KCl}$ from $\mathrm{CeO}_{2}$ in which the post-VSD product was a loose powder. Consequently, $\mathrm{KOH}$ additions should be minimized.

Potassium data indicate that the use of $50 \%$ molar excess $\mathrm{KOH}$ leads to increases in residual $\mathrm{K}$, even when heated for $180 \mathrm{~min}$ at temperature. Reducing the amount of molar excess $\mathrm{KOH}$ enabled a net reduction in the residual $\mathrm{K}$ when a 180 -min heating cycle was used. However, when the heating cycle was decreased to $120 \mathrm{~min}$, even at only $10 \%$ molar excess $\mathrm{KOH}$, the residual $\mathrm{K}$ concentration increased. Consequently, consistent with the residual fluoride data, the furnace cycle time for the quantity of material in the boat should be $180 \mathrm{~min}$. The volume of material in the boat for these tests with $\mathrm{CeO}_{2}$ is comparable to what would be expected for operations in HB-Line. Empirical observations of the post-VSD product do not indicate a correlation between residual $\mathrm{K}$ and product consistency.

Analysis of the S002250 material for fluoride content revealed that the material contained $5.14 \mathrm{wt} \%$ fluoride instead of $4.2 \mathrm{wt} \%$, as was initially reported from prompt gamma analysis. Because the first two tests were completed prior to the analysis of the initial material, the first two tests were performed at a molar excess of $\mathrm{KOH}$ of $21-22 \%$ instead of the targeted excess of $50 \%$. Issues were encountered with the vacuum system and the first tests were completed with inadequate vacuum ( $>5$ torr). With inadequate vacuum, a $20 \mathrm{~g}$ test saw a fluoride reduction of $42 \%$ after $120 \mathrm{~min}$ at $975^{\circ} \mathrm{C}$; under similar conditions, the fluoride concentration was reduced by only $23 \%$ for an $80-\mathrm{g}$ test.

When tests with $80-100 \mathrm{~g}$ of feed material were completed with adequate vacuum ( $\sim 0.06$ torr), improved fluoride removal was observed. After 15 min at $975^{\circ} \mathrm{C}$ with $21 \%$ molar excess $\mathrm{KOH}$, fluoride was reduced by $72 \%$ to $14,300 \mathrm{mg} / \mathrm{kg}$. This level of fluoride removal does not meet the MOX feed specification of $7500 \mathrm{mg} / \mathrm{kg}$. After $35 \mathrm{~min}$ and $65 \mathrm{~min}$ at $975{ }^{\circ} \mathrm{C}$ with $49 \%$ molar excess $\mathrm{KOH}$, fluoride was reduced by $91 \%$ and $98 \%$, respectively, to $4410 \mathrm{mg} / \mathrm{kg}$ and $1070 \mathrm{mg} / \mathrm{kg}$, respectively. This meets the MOX feed specification. Extended distillation times should yield even lower residual fluoride concentrations. Extrapolation of the available data shows that the fluoride concentration would be reduced to less than $250 \mathrm{mg} / \mathrm{kg}$ in about $90 \mathrm{~min}$. 
SRNL evaluated four disposable liner designs at the pilot scale for easy disposal of distilled salt. Two designs were superior. One design employed a disposable liner matched to a re-usable tapered end cap that fits against the tapered region in the VSD vacuum chamber. The second design uses one liner in the narrow section of the vacuum chamber and extends into the wider section of the chamber, plus a liner in the wider section of the chamber. The second design does not require the liner to be fit over the tapered end cap in the glovebox. Because of issues related to the liner getting stuck in the vacuum chamber and potential corrosion of a liner in the narrow section of the vacuum chamber, the preferred design uses the tapered end cap fitted to the disposable liner.

The liner designs were effective in collecting greater than $99.9 \%$ of the salt. However, even this small amount of salt over time could lead to the liner getting stuck in the vacuum chamber. Consequently, it is recommended that damp polishing or wiping of the cooled zone be completed after each unit operation to avoid salt accumulation in the vacuum chamber.

The use of $\mathrm{KOH}$ in the process increases the chemical attack and corrosion of the Alloy 600 product boats and, to a lesser degree, the vacuum chamber. As with testing that did not use $\mathrm{KOH}$, the boat surface eventually passivates to the extent such that the life of an Alloy 600 boat would exceed 100 production cycles. However, it is not immediately known whether the amount of corrosion products deposited by the boat into the material will have a negative effect on meeting the MOX feed specification. If necessary, an alumina boat material can be used which is much more resistant to chemical attack.

Water is a byproduct of the reaction between $\mathrm{KOH}$ and multivalent halide salts. The presence of water in the off gas stream from the vacuum chamber can have a negative impact on the vacuum pump, especially the type of dry pump used in HB-Line. Testing demonstrated that a calcium sulfate absorbent can be used in line to remove most of the moisture. Trace amounts of moisture still pass through the absorbent and condense in the dry pump. However, the quantity of moisture reaching the dry vacuum pump is less than what was observed for chloride salt removal studies without $\mathrm{KOH}$. As a result, the use of the dry vacuum pump in conjunction with the absorbent should be adequate for fluoride-removal trials in HB-Line. Calcium sulfate can be dried in a muffle furnace and recycled.

During pilot-scale testing, deposition of salts on the vacuum chamber door occurred, likely due to the increased volatility of $\mathrm{KOH}$ compared to that of $\mathrm{NaCl}$ and $\mathrm{KCl}$. The salt on the door rapidly absorbs moisture from the air, suggesting that the deposits are $\mathrm{KOH}$. Analyses indicate that the salt quantity is less than one gram. In addition to cleaning, the presence of salt on the door poses a potential safety issue. The deposited salt is a high-surface-area material which is reactive to water. When the material on the door is scraped with a spatula in a moist atmosphere, the material sparks. When the material is contacted with a stream of water, it flares. However, when it has unrestricted contact with the atmosphere, the material absorbs moisture and passivates within several minutes. Pilot-scale testing has shown that the material can be passivated with the door closed by allowing air into the chamber during the lengthy period of system cooling. Systematic testing in a configuration comparable to HB-Line has not yet been conducted. 


\subsection{Future Work}

The next major step for the program entails pilot-scale testing with radioactive materials in HB-Line. HB-Line has a sample of the S002250 material available. To be ready to complete this demonstration, the following tasks are recommended.

1) Finalize boat design. Make a decision on whether the use of an Alloy 600 boat is adequate. Modify the 10.5-inch boat design to include a heat shield attached to the boat, similar to what was used previously in HB-Line on the 12-inch boat. If Alloy 600 is not adequate due to product contamination, pursue the procurement of an alumina liner for the boat. Alumina coatings are not currently considered adequately robust for the boat.

2) Passivation of door residues. The deposition of high-surface area residues on the vacuum chamber door presents a potential safety issue due to the reactivity of the material with liquid water (not vapors). During testing, though, it was shown that the material passivates readily upon exposure to air for about 10 minutes. Testing is needed to define a passivation procedure for equipment configured comparable to what will be operated in HB-Line.

3) Compaction tool for liners. The use of liners, while a great benefit when it comes to salt removal, can pose a sharps issue upon compaction. One option would involve the use of over-gloves in the glovebox. If this is deemed too cumbersome of an operation, a tool must be developed to safely compact the liners for disposal.

4) Evaluate the benefits of using a 240-min furnace cycle instead of a 180-min cycle at the pilot scale. Will the increased time reduce residual $\mathrm{K}$ and improve product consistency?

5) Evaluate the impact of distillation at $950^{\circ} \mathrm{C}$ instead of $975^{\circ} \mathrm{C}$. Can the updated MOX feed specification of $250 \mathrm{mg} / \mathrm{kg}$ be achieved within $3-4 \mathrm{~h}$ at temperature?

\subsection{References}

1. E. Garcia, V. Dole, and J. McNeese, "Separation of Plutonium from Chloride Salts is Demonstrated by High-Temperature Vacuum Distillation Method," The Actinide Research Quarterly of the Nuclear Materials Technology Division, Los Alamos National Laboratory (Summer 1995).

2. B. R. Westphal, K. C. Marsden, J. C. Price, and D. V. Laug, "On the Development of a Distillation Process for the Electrometallurgical Treatment of Irradiated Spent Nuclear Fuel," Nucl. Eng. \& Tech., 2008, 40(3), 163-174.

3. J. E. Therrell, "Vacuum Salt Distillation (VSD) in HB-Line," SRNS-N2000-2011-00032 (February 15, 2011).

4. R. A. Pierce, T. D. Caldwell, and D. J. Pak, "Application of Vacuum Salt Distillation Technology for the Removal of Fluoride," SRNL-STI-2011-00469 (August 2011).

5. K. P. Burrows, "Pilot Scale Demonstration of Vacuum Salt Distillation Technology for the Removal of Fluoride Salts from Plutonium Oxide," Technical Task Request NMMD-HTS2012-3 192, Rev 0 (February 6, 2012). 
6. R. A. Pierce, "Task Technical and Quality Assurance Plan for a Pilot-Scale Demonstration of Vacuum Salt Distillation for the Removal of Fluoride Salts from Plutonium Oxide," SRNL-RP-2012-00036 (February 2012).

7. S. McAlhany, "Mixed Oxide Fuel Fabrication Facility (MFFF) - H-Area/K-Area Plutonium Oxide Powder Interface Control Document," G-ESR-H-00189, Rev. 0 (June 2012).

8. D. C. Castiglione and R. A. Pierce, "Non-Radioactive Pilot-Scale Studies for the Vacuum Distillation of Chloride Salts," SRNL-STI-2010-00075 (March 2010).

9. J. E. Laurinat, "Vapor Pressures for $\mathrm{LiF}, \mathrm{Li}_{2} \mathrm{O}, \mathrm{LiOH}$, and $\mathrm{KOH}$," SRNL-L4222-2011-00006 (February 15, 2011).

10. D. C. Castiglione and R. A. Pierce, "Non-Radioactive Studies of Sodium Peroxide Fusion for Accelerated Sample Dissolution," SRNL-STI-2010-00164 (June 2010).

11. R. A. Pierce and T. B. Edwards, "Vacuum Salt Distillation Intermediate-Scale and FullScale Prototype Testing," SRNL-STI-2010-00753 (December 2010).

12. R. A. Pierce, "Validation Testing of VSD Equipment Prior to Installation in HB-Line," SRNL-TR-2010-00394 (December 2010). 


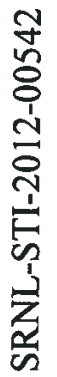

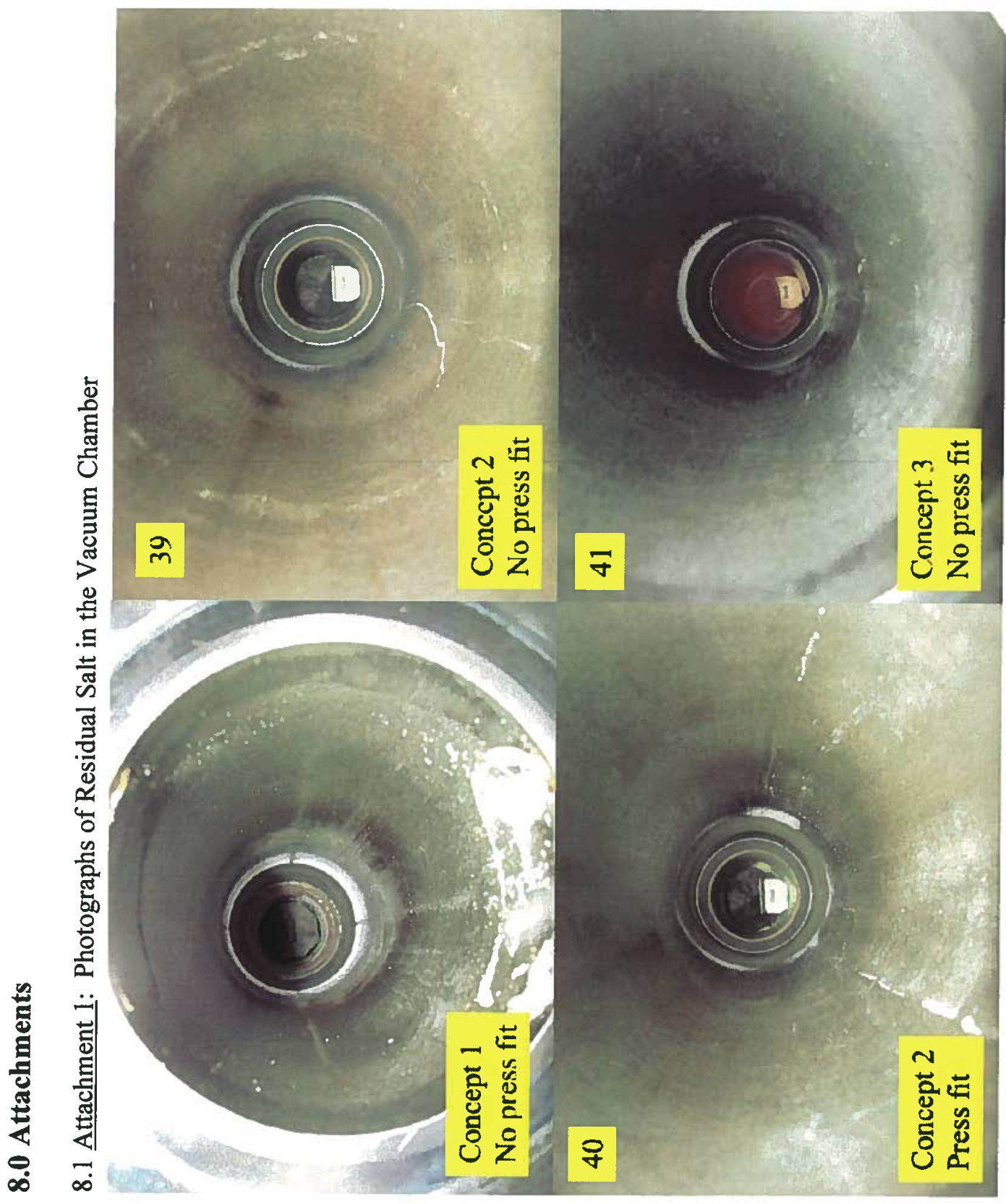


告

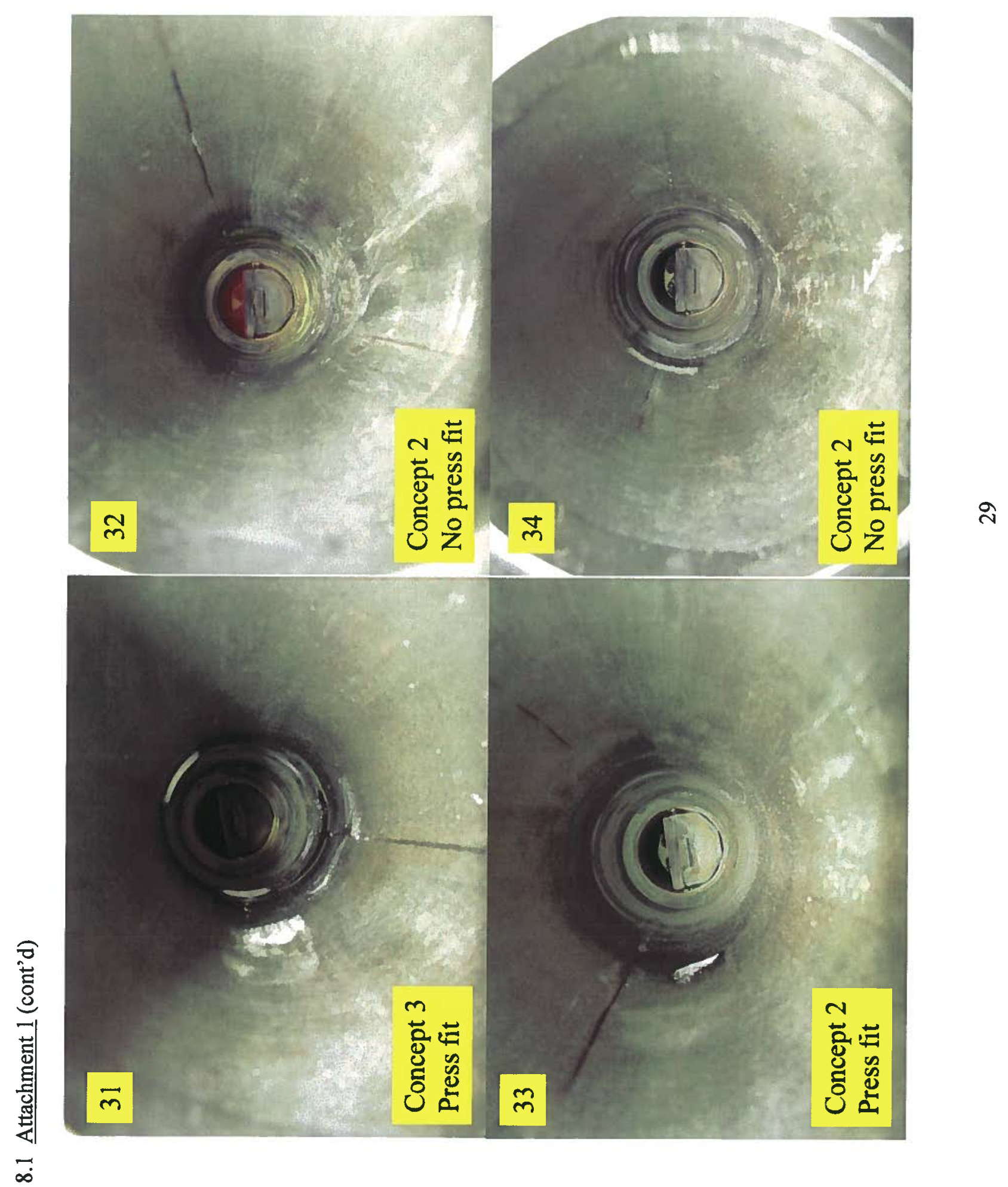




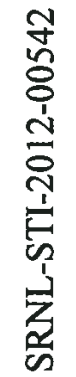

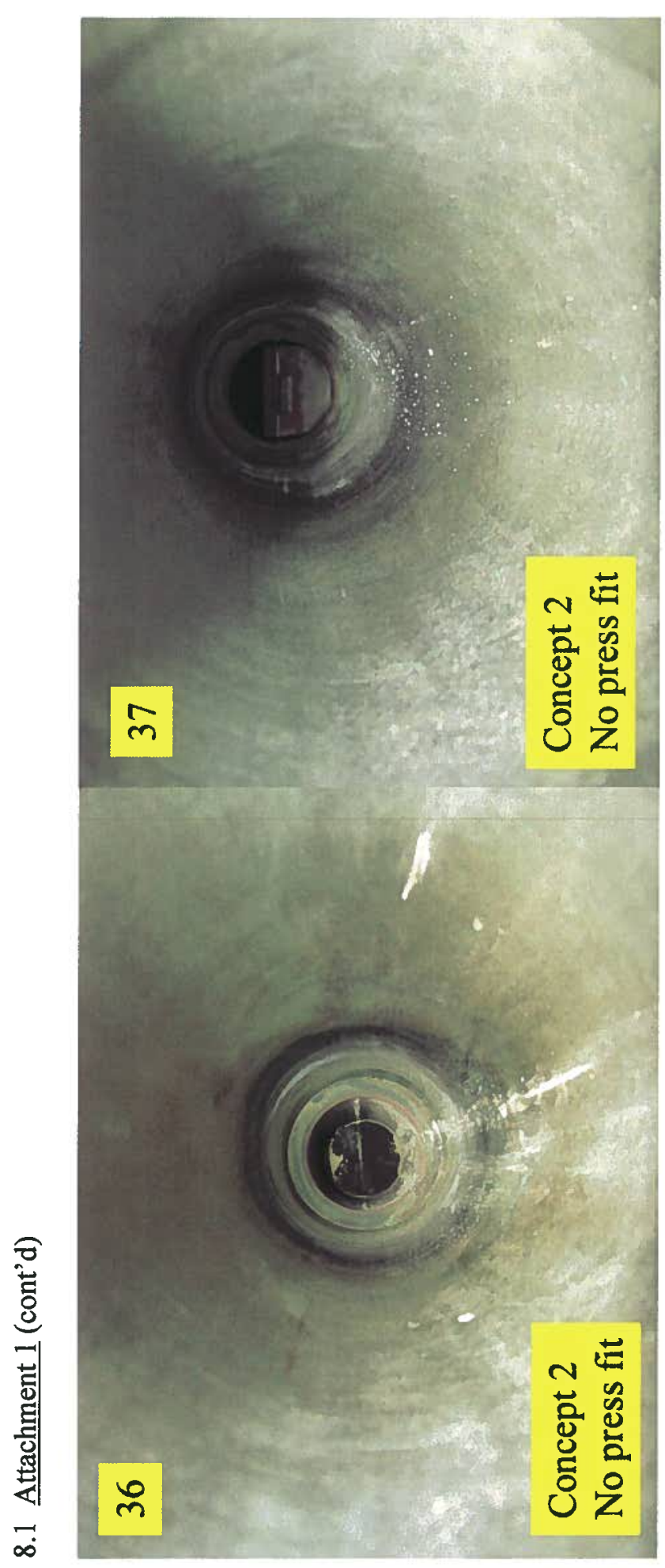




\section{Distribution:}

S. D. Fink, 773-A

K. M. Fox, 999-W

B. J. Giddings, 786-5A

C. C. Herman, 999-W

S. L. Marra, 773-A

F. M. Pennebaker, 773-42A

W. R. Wilmarth, 773-A

E. A. Kyser, 773-A

T. S. Rudisill, 773-A

R. A. Pierce, 773-A

J. H. Scogin, 773-A

M. C. Thompson, 773-A

M. L. Crowder, 773-A

Records Administration (EDWS)

C. Wilson, 773-A
W. E. Harris, 704-2H

J. B. Schaade, 704-2H

G. J. Zachman, 225-7H

P. B. Andrews, 704-2H

S. J. Howell, 221-H

W. G. Dyer, 704-2H

M. J. Swain, 703-H

M. J. Lewczyk, 221-H

J. L. O'Conner, 704-2H

S. L. Hudlow, 221-H

W. H. Clifton, 704-2H

K. P. Burrows, 704-2H

K. J. Gallahue, 221-H

J. E. Therrell, 704-2H

J. W. Christopher, 704-2H

J. E. Elkourie, 704-2H

S. B. Beck, 249-7H

S. A. Thomas, 703-46A 